\title{
Erscheinungsformen nichtstaatlicher Einflüsse auf die staatliche Gesetzgebung
}

Matthias Rossi"

\section{Einleitung}

Erscheinungsformen nichtstaatlicher Einflüsse auf die staatliche Gesetzgebung vorzustellen, ist eine ebenso undankbare wie notwendige Aufgabe für den primär normativ arbeitenden Rechtswissenschaftler. Undankbar, weil schon erste Überlegungen zeigen, dass die Erscheinungsformen derart vielfältig sind, dass sie kaum vollständig zu erfassen, geschweige denn überschneidungs- und wiederholungsfrei zu systematisieren sind. Dabei sind Überlegungen hier eigentlich gar nicht angebracht, sondern vielmehr Beobachtungen gefragt. Denn nicht (nur) normativ vorgesehene Mittel nichtstaatlicher Einflüsse, sondern (vor allem) deren tatsächlich vorkommende Erscheinungsformen sollen dargestellt werden. Angesprochen ist also weniger die Rechts- als vielmehr die Sozialwissenschaft, die entsprechend geschult und methodisch bewandert ist. Gleichwohl ist die Aufgabe auch dem Rechtswissenschaftler eine notwendige, weil es sich stets zu vergewissern gilt, ob das Sein noch dem Sollen entspricht oder ob die normative Ordnung (in diesem Zusammenhang also die Summe der Vorschriften über die staatliche Rechtsetzung) nicht möglicherweise nur noch eine Idee, ja vielleicht nur noch eine Illusion ist, die mit der Realität auch ihrer Funktionen, insbesondere ihrer legitimierenden und Verbindlichkeit stiftenden Funktionen, verlustig gegangen ist.

Soll das Thema innerhalb der zeitlichen Grenzen eines Vortrags bzw. der umfänglichen Grenzen eines Beitrags nicht nur assoziativ behandelt werden, bedarf es einerseits einer inhaltlichen Präzisierung (1.) und zugleich andererseits einer multiperspektivischen Betrachtung (2.).

* Meinem Mitarbeiter, Herrn Chrisłoph Nägele, danke ich vielmals für die Unterstützung. 


\section{Präzisierung des Themas}

Die Erscheinungsformen nichtstaatlicher Einflüsse auf die staatliche Gesetzgebung sollen hier im Kontext des Tagungsbandes, im Kontext also der Ausgliederung von Gesetzgebungstätigkeiten aus den staatlichen Organen an private Rechtsanwaltskanzleien, beschrieben werden. Es würde das Thema wohl aber verfehlen, wegen dieses Zusammenhangs allein sonstige Formen der Ausgliederung oder nur andere Mittel der advokatorischen Einflussnahme in den Blick zu nehmen. Vielmehr wird das Thema weit vielschichtiger, differenzierter und ergebnisoffener begriffen: Möglicherweise erscheint das provokative, wenn auch mit Fragezeichen versehene Tagungsthema „Gesetzgebung durch Rechtsanwälte" bei einer Gesamtbetrachtung aller Erscheinungsformen nichtstaatlicher Einflüsse auf die staatliche Gesetzgebung weit weniger anrüchig, als es auf den ersten Blick erscheint. Das Oberthema selbst verlangt also nicht nach einer Eingrenzung, sondem eher nach einer möglichst breiten Behandlung. Dafür spricht auch eine kurze Betrachtung der einzelnen Themenkomponenten:

Hervorzuheben ist zunächst, dass nicht etwa "private“, sondern "nichtstaatliche“ Einflüsse auf die staatliche Gesetzgebung zu untersuchen sind. Dies schließt bei allen Abgrenzungsschwierigkeiten etwa auch die Kirchen oder die „öffentliche Meinung" mit ein.

Näher zu betrachten ist sodann die Begrifflichkeit „staatliche Gesetzgebung“. Sie ließe sich in mehrfacher Hinsicht eng verstehen: Erstens könnte der Begriff „Gesetzgebung" nur auf die formelle Gesetzgebung durch Parlamente bezogen sein und bspw. die Verordnungsgebung ausklammern. Zweitens könnte die Umschreibung „staatlich“ im klassischen Sinne nur die Rechtsetzung in und durch Staaten meinen und insofern die kommunale Rechtsetzung ebenso ausnchmen wie die Normsetzung in der Europäischen Union. Die Umschreibung könnte drittens sogar nur auf die Bundesebene bezogen sein und die Gesetzgebung der Bundesländer außer Acht lassen. Doch all diese begrifflich möglichen Einschränkungen würden dem Inhalt des Themas nicht gerecht werden. Vor dem Hintergrund, dass der Erlass von Rechtsverordnungen mit der „Anhörung der beteiligten Kreise"si eine formal vorgesehene Einflussmöglichkeit Privater vorsieht und auch unabhängig hiervon privater Sachverstand bei den oft technischen Rechtsverordnungen sehr viel eher gefragt ist als bei der häufig abstrakten parlamentarischen Gesetzgebung, soll der Begriff der Gesetzgebung hier im materiellen Sinne verstanden werden, zumal der nichtstaatliche Einfluss auf die materiwie §6 WRMG. 
elle Gesetzgebung des Bundes und der Länder mit der formellen Gesetzgebung zumindest vernetzt ist und in einem wechselseitigen Abhängigkeitsverhältnis zu ihr steht. Eine isolierte Darstellung des einen oder des anderen Bereiches macht deshalb ebenso wenig Sinn wie eine Darstellung der nationalen Ebene unter Ausklammerung der europäischen Ebene.

Deshalb wird auch die Rechtsetzung in der Europäischen Union in die „staatliche Gesetzgebung" einbezogen, ohne dass damit der Europäischen Union ein Staatscharakter zugesprochen werden soll. Denn unabhängig davon, ob mit Verordnungen eine unmittelbar geltende, die nationalen Legislativorgane nicht mehr berührende Rechtsform gewählt wird oder diese Adressaten der Umsetzungspflichten von Richtlinien sind, sind nichtstaatliche Akteure wegen des räumlichen Geltungsbereichs und des sachlichen Anwendungsvorrangs des Unionsrechts gut beraten, ihren Einfluss möglichst schon auf europäischer Ebene geltend zu machen. Die Bedeutung der europäischen Ebene für die nationale Gesetzgebung muss wohl nicht mehr betont werden und wurde längst von nichtstaatlichen Interessenträgern erkannt und auch genutzt - viclleicht sogar früher als von staatlicher Seite. Im Übrigen führte die Verncinung der in diesem Rahmen überhaupt nicht relevanten Frage der Staatlichkeit der Europäischen Union dazu, sie statt als Einflussobjekt als Einflusssubjekt behandeln zu müssen. Zu untersuchen wäre dann, welche Einflussmöglichkeiten die Europäische Union auf die staatliche Gesetzgebung hat - ein Aspekt, der im Kontext des Oberthemas ohne Bedeutung ist. ${ }^{2}$ Dagegen soll der mehrfach gemittelte Einfluss nichtstaatlicher Wirkeinheiten auf den Abschluss völkerrechtlicher Verträge jedenfalls in das Bewusstsein gerückt werden, weil er - etwa im Klimaschutzrecht -

2 Ebenfalls nicht dargestellt werden können als spezifisches europäisches Phänomen die Erscheinungsformen des sog. Komitologieverfahrens. Dieses soll den für die Umsetzung europäischer Rechtsakte zuständigen Mitgliedstaaten Hilfe sein. indem es Durchführungsmaßnahmen vorgibt. Dabei dienen ca. 300 mit Vertretern der Regierungen der Mitgliedstaaten und Experten besetzte Verwaltungs- und Fachausschüsse als Bindeglied zwischen den Mitgliedstaaten und der Kommission. Grundlage für die Zusammenarbeit ist dabei der Beschluss des Rates vom 28. Juni 1999 zur Festlegung der Modalităten für die Ausubbung der der Kommission übertragenen Durchführungsbefugnisse 1999/468/EG. zuletzt geändert durch Art. 1 ÄndB 2006/512/EG vom 17. 7. 2006 (AB1. Nr. L 200 S. 11). Ausgehend von einem Vorschlag der Kommission wird je nach Regelungsmaterie eines von drei Verfahren eingeleitet, in denen die Regierungen der Mitgliedstaaten und die Kommission jeweils unterschiedlich ausgestaltete Mitwirkungsrechte haben. Man unterscheidet zwischen dem Beratungsverfahren mit einer rein beratenden Funktion des Ausschusses (Art. 3 des Beschlusses), dem Verwaltungsverfahren mit einer größeren Kontrollfunktion des Rates (Art. 4 des Beschlusses) und dem Regelungsverfahren, in dem es der ausdrücklichen Zustimmung des Ausschusses zum Kommissionsvorschlag bedarf (Art. 5 und der 2006 eingeführte Art. 5a des Beschlusses). Nach dem Vertrag von Lissabon soll das Komitologieverfahren neu geregelt werden. Maßstab dafür ist Art. 290 AEUV. der neue Regelungen für delegierte Rechtsakte enthält. 
zu einer weitgehenden Determinierung des staatlichen Gesetzgebers führt. Zusammenfassend sei also festgehalten, dass alle Erscheinungsformen des nichtstaatlichen Einflusses auf die Normsetzung im Bundesstaat einschließlich der Europäischen Union thematisiert werden sollen.

Schließlich bedarf auch die dritte Themenkomponente der Präzisierung. Der Begriff „Einfluss“ impliziert zunächst, dass neben unmittelbaren vor allem auch mittelbare Einwirkungsmöglichkeiten in den Blick zu nehmen sind. Darüber hinaus weist er auf eine bestimmte Richtung hin, bildhaft gesprochen auf eine Einbahnstraße aus der nichtstaatlichen in die staatliche Sphäre. Damit suggeriert er eine einseitige Aktion auf nichtstaatlicher und eine Absorption oder Reaktion auf staatlicher Seite. Eine solche Perspektive alleine zeichnete allerdings ein defizitäres Bild. Um der Praxis gerecht zu werden, muss die Darstellung mehrere Dimensionen und Bewegrichtungen des Einflusses erfassen. Klargestellt sei deshalb, dass die staatliche Seite durchaus nichtstaatlichen Sachverstand aus eigenem Antrieb heranzieht, ${ }^{3}$ ohne dass es dazu eines besonderen Druckes der nichtstaatlichen Seite bedürfte. Dies verdeutlicht freilich auch das Tagungsthema "Gesetzgebungsoutsourcing", welches ein Phänomen auf staatlicher Seite beschreibt, bei dem sich der Gesetzgeber bzw. regelmäßig die Ministerialverwaltung bei der Erstellung von Gesetzesentwürfen des Sachverstandes außerhalb staatlicher Macht stehender privater Wirkeinheiten bedient.

\section{Multiperspektivische Betrachtung}

Dem so verstandenen Thema kann nur durch eine multiperspektivische Betrachtung gerecht werden. Denn ebenso sinnvoll, wie bspw. eine historische Darstellung über die Entwicklung nichtstaatlicher Einflüsse auf die staatliche Gesetzgebung erscheint, ließe sich in zeitlicher Hinsicht mit den Momenten der Einflussnahme an die verschiedenen Phasen des Gesetzgebungsverfahrens anknüpfen. Darüber hinaus könnten unmittelbare und mittelbare Instrumente zur Gliederung in den Fokus genommen werden oder zwischen legalen und illegalen Einflussmöglichkeiten differenziert werden. Ebenso gut ließen sich intendierte Ziele und erreichte Wirkungen der verschiedenen Erscheinungsformen als Fluchtpunkt für eine umfassende Darstellung wählen.

Im Folgenden soll aber von vorneherein kein Versuch unternommen werden, die verschiedenen Erscheinungsformen mittels eines einzigen Differenzierungskrite-

3 Siehe hierzu umfassend Andreas Voßkuhle, Sachverständige Beratung des Staates, in: Josef Isensee/Paul Kirchhof (Hrsg.), Handbuch des Staatsrechts, Band III, 3. Auflage $2005, \S 43$. 
riums zu erfassen. Stattdessen werden vier verschiedene Aspekte in den Vordergrund gestellt. Jeder Anspruch auf Wiederholungsfreiheit geht damit freilich ebenso verloren wie die Hoffnung auf eine in sich stimmige oder gar geschlossene Phänomenologie nichtstaatlicher Einflüsse auf die staatliche Rechtsetzung. Geboten werden kann hier nur ein Panoptikum an besonderen Schnittstellen zwischen staatlicher Gesetzgebung und privater Einflussnahme (II.), an Akteuren (III.), Adressaten (IV.) und Instrumenten (V.), ein Panoptikum, das aus der Rückschau dann sechs abschließende Überlegungen evoziert (VI.).

II. Besondere Schnittstellen zwischen staatlicher Gesetzgebung und privater Einflussnahme

Die demokratische Grundordnung der Bundesrepublik Deutschland lässt sich staatstheoretisch als repräsentative Demokratie beschreiben. Besonderes Kennzeichen dieser Demokratieform ist, dass das Volk nach Art. 20 Abs. 2 Satz 1 GG zwar Inhaber aller Staatsgewalt ist, diese Staatsgewalt aber gemäß Art. 20 Abs. 2 Satz 2 GG unmittelbar nur in Wahlen und im Übrigen mittelbar durch Organe ausübt. Begreift man die Rechtsetzung durch diese Organe als ,staatliche Gesetzgebung" i.S. des Tagungsthemas, kann jede Einwirkung von Einzelnen unabhängig davon, ob sie individuell oder kollektiv erfolgt, als private Einflussnahme auf die staatliche Gesetzgebung charakterisiert werden. Das Tagungsthema gewinnt seine gesamte Bedeutung insofern vor dem Hintergrund der repräsentativen Demokratie und verliert an Brisanz, wenn man weitere und andere Aspekte der demokratischen Staatsform in den Vordergrund rückt. Zwei expliziert normierte und dadurch formalisierte Einflussmöglichkeiten sollen diesbezüglich Erwähnung finden - direktdemokratische Instrumente auf der einen Seite (1.) und Petitionsrechte auf der anderen Seite (2.).

\section{Direktdemokratische Instrumente}

Unmittelbarste Form des nichtstaatlichen Einflusses auf die staatliche Gesetzgebung sind direktdemokratische Elemente, ${ }^{4}$ namentlich also Abstimmungen in Form von Volksinitiativen, Volksbefragungen und Volksentscheiden. Freilich ließe sich die - nicht nur begrifflich bedeutsame - Frage aufwerfen, ob bei diesen „klassischen“ direktdemokratischen Instrumenten überhaupt noch von einem

Vgl. zur direkten Demokratie im Grundgesetz umfassend Peter Krause, Verfassungsrechtliche Möglichkeiten unmittelbarer Demokratie, in: Josef Isensee/Paul Kirchhof (Hrsg.), Handbuch des Staatsrechts, Band III, 3. Auflage 2005, § 35. 
nichtstaatlichen Einfluss auf die staatliche Gesetzgebung gesprochen werden kann oder ob nicht vielmehr das Volk selbst als (Staats-)Organ tätig wird und insofern die Schwelle des nur mittelbaren Einflusses überschritten wird hin zur unmittelbaren staatlichen Gesetzgebung. Doch diese Frage soll im Rahmen dieses Panoptikums einmal unbeantwortet bleiben, zumal wohl doch eine nach der konkreten Ausgestaltung der Abstimmung differenzierte Beantwortung geboten ist. Festzuhalten ist hier nur, dass direktdemokratische Einflussmöglichkeiten auf den verschiedenen staatlichen Ebenen in sehr unterschiedlichem Maße zur Verfügung stehen, wobei im Folgenden nur die Bundesebene (a.), die Landesebene (b.) und die Ebene der Europäischen Union (c.) skizziert werden, während die kommunale Ebene mit ihren z.T. recht weit reichenden Möglichkeiten der Bürgerbegehren, Bürgerentscheide und Bürgeranträge ausgeblendet wird.

\section{a) Direktdemokratische Instrumente auf Bundesebene}

Die Demokratie auf Bundesebene ist im Ergebnis strikt parlamentarisch ausgestaltet. Zwar lenkt Art. 20 Abs. 2 Satz 2 GG die Ausübung der dem Volk von Art. 20 Abs. 2 Satz 1 GG zugesprochenen Staatsgewalt in zwei geregelte Bahnen, indem er - sprachlich gleichstufig nebeneinander stehend - dem Volk die Möglichkeiten zuspricht, die Staatsgewalt ,in Wahlen und Abstimmungen“" auszuüben, also nicht nur personelle Entscheidungen über die Zusammensetzung der Organe, namentlich des Bundestags, sondern auch sachliche Entscheidungen über konkrete Fragen und Gesetzesvorhaben zu treffen. Nach ganz überwiegender Meinung wird mit der Erwähnung der Abstimmungen in Art. 20 Abs. 2 GG aber nur der Handlungstypus als solcher verfassungsrechtlich legitimiert, nicht hingegen sein Gebrauch operationalisiert. Erforderlich sei mindestens eine Konkretisierung in einem Gesetz, nach überwiegender Meinung gar im Grundgesetz selbst.

Die insofern einzige verfassungsunmittelbar normierte Möglichkeit einer Abstimmung, sieht man einmal von dem Sonderfall des Art. $146 \mathrm{GG}$ ab, betrifft die praktisch nicht besonders relevante Frage der Neugliederung des Bundesgebiets nach Art. 29 GG. Abstimmungsberechtigt sind dabei allerdings nur die Bürger der betroffenen Bundesländer, so dass von einer Ausübung der Staatsgewalt durch das Staatsvolk i.S.d. Art. 20 Abs. 2 GG nicht, jedenfalls nicht zwangsläufig, gesprochen werden kann.

Im Übrigen weist das Grundgesetz dem Staatsvolk weder ein Gesetzesinitiativrecht in Form einer Volksinitiative zu noch besteht für das Volk die Möglichkeit, per Volksentscheid verbindlich oder empfehlend über Gesetzentwürfe in Ab- 
stimmungen zu entscheiden. Vielmehr übt das Volk seine Gewalt auf Bundesebene allein durch die von ihm gewählten und durch eine ununterbrochene Legitimationskette mit ihm verbundenen Repräsentanten aus. ${ }^{5}$

\section{b) Direktdemokratische Instrumente auf Landesebene}

Anders verhält es sich auf der Ebene der Bundesländer. Alle Länderverfassungen sehen - wenn auch in sehr unterschicdlichem Umfang - direktdemokratische Elemente vor, ${ }^{6}$ ohne dass dies etwa gegen die Homogenitätsklausel des Art. 28 Abs. 1 GG verstieße? Vielmehr unterfällt es der Verfassungsautonomie der Bundesländer und ist Ausdruck ihrer Staatlichkeit, das Nebeneinander von repräsentativen und plebiszitären Elementen selbst zu bestimmen.

Dabei kann es als unmittelbarer Einfluss auf die staatliche Gesetzgebung begriffen werden, dass das Volk den Landesgesetzgeber mittels eines Volksbegehrens oder einer Volksinitiative mit einem bestimmten Thema oder einem konkreten Gesetzentwurf befassen kann oder sogar - weiter gehend - selbst verbindlich über einen Gesetzentwurf abstimmen kann.

Jedenfalls soweit diese Instrumente fakultativ ausgestaltet sind, also der Entscheidung des Volks bzw. seiner Teile überlassen sind, erscheint es auch gerechtfertigt, sie der nichtstaatlichen Seite zuzurechnen und sie somit als Möglichkeit der Beeinflussung der staatlichen Gesetzgebung zu begreifen. Denn auch nach den Länderverfassungen ist die Demokratie ganz überwiegend repräsentativ ausgestaltet und nur um einzelne direktdemokratische Elemente ergänzt. Originärer Gesetzgeber ist demnach das jeweilige Landesparlament, so dass eine Gesetzgebung durch das Volk fast schon als Fremdkörper, jedenfalls aber als von außerhalb auf die staatliche Gesetzgebung einwirkend, erscheint. Soweit ver-

5 Vgl. zur repräsentativ ausgestalteten Demokratic des Grundgesetzes grundlegend ErnstWolfgang Böckenförde, Demokratische Willensbildung und Repräsentation, in: Josef Isensee/Paul Kirchhof (Hrsg.). Handbuch des Staatsrechts, Band III, 3. Auflage 2005, $\S 34$ und zum Erfordernis der ununterbrochenen Legitmationskette ebenda Rn. 17 sowie ders., Demokratie als Verfassungsprinzip, in: Josef Isensee/Paul Kirchhof (Hrsg.), Handbuch des Staatsrechts, Band II, 3. Auflage 2004, § 24 Rn. 16 ff.

6 Peter Krause, Verfassungsrechtliche Möglichkeiten unmittelbarer Demokratie, in: Josef Isensee/Paul Kirchhof (Hrsg.), Handbuch des Staatsrechts, Band III, 3. Auflage 2005, $\S 35$ Rn. 29 ff. m.w.N. und dort Fn. 109 mit einer Übersicht über die relevanten landesverfassungsrechtlichen Normen.

7 Dazu Peter Krause. Verfassungsrechtliche Möglichkeiten unmittelbarer Demokratie, in: Josef Isensee/Paul Kirchhof (Hrsg.). Handbuch des Staatsrechts. Band III, 3. Auflage 2005, § 35 Rn. 27 m.w.N. 
schiedene Landesverfassungen dagegen Referenden obligatorisch vorschreiben oder in die Entscheidungsmacht nicht des Volkes, sondern des Parlaments stellen, ${ }^{8}$ ließe sich auch über eine Einbeziehung solcher direktdemokratischen Entscheidungen in die staatliche Gesetzgebungsgewalt nachdenken.

\section{c) Direktdemokratische Instrumente auf Ebene der Europäischen Union}

Auf europäischer Ebene besteht mit dem neu geschaffenen Art. 11 Abs. 4 EUV seit dem Inkrafttreten des Vertrags von Lissabon erstmals die Möglichkeit, dass organisierte Unionsbürger die Rechtsetzung der Europäischen Union in direktdemokratischer Form beeinflussen. Dies ist umso bedeutsamer, als die europäische Rechtsetzung wiederum die nationale Gesetzgebung beeinflusst.

Art. 11 Abs. 4 EUV räumt den Unionsbürgern zwar kein echtes Initiativ-, immerhin aber ein Vorschlagsrecht ein. „Unionsbürgerinnen und Unionsbürger, deren Anzahl mindestens eine Million betragen und bei denen es sich um Staatsangehörige einer erheblichen Anzahl von Mitgliedstaaten handeln muss, können die Initiative ergreifen und die Europäische Kommission auffordern, im Rahmen ihrer Befugnisse geeignete Vorschläge zu Themen zu unterbreiten, zu denen es nach Ansicht jener Bürgerinnen und Bürger eines Rechtsakts der Union bedarf, um die Verträge umzusetzen“, heißt es in der Norm etwas kompliziert und durchaus konkretisierungsbedürftig.

Konkretisiert werden soll diese neu eingeführte Initiativmöglichkeit durch eine nach Art. 24 Abs. I AEUV zu erlassende Verordnung. Bis zu deren Inkrafttreten sind Initiativen von Unionsbürgern noch nicht möglich. Am 31. März 2010 wurde ein erster Entwurf der Verordnung" vorgelegt, aber noch nicht verabschiedet. Folgende Eckpunkte sind vorgesehen: Den Initianten der Bürgerinitiative steht ein Zeitraum von 12 Monaten zum Sammeln der notwendigen Unterschriften zur Verfügung. Der primärrechtliche Passus „einer erheblichen Anzahl an Mitgliedsstaaten" wird dahingehend konkretisiert, dass die Unterschriften von Bürgern aus mindestens einem Drittel der Mitgliedsstaaten stammen und für jedes Land ebenso bestimmte Mindestanzahlen an Unterschriften, abhängig von der Zahl der tie, in: Josef Isensee/Paul Kirchhof (Hrsg.), Handbuch des Staatsrechts, Band III, 3. Auflage $2005, \$ 35 \mathrm{Rn} .36 \mathrm{ff}$.

9 Europäische Kommission, Vorschlag für eine Verordnung des Europäischen Parlaments und des Rates über die Bürgerinitiative vom 31.03.2010, $\mathrm{KOM}(2010) 119$ und vorgehend Kommission der Europäischen Gemeinschafien, Grünbuch zur Europäischen Bürgerinitiative vom 11.11.2009, $\mathrm{KOM}(2009), 622$. 
Abgeordneten dieses Landes im Europäischen Parlament, erbracht werden müssen. Der Kommission sollen drei Monate eingeräumt werden, um über die Zulässigkeit der Initiative zu entscheiden.

Unabhängig von ihrer konkreten Ausgestaltung ist im Kontext dieses Tagungsbandes hervorzuheben, dass die Initiativbefugnis nach Art. 11 Abs. 4 EUV in mehrfacher Hinsicht beschränkt ist und vor allem dic Kompetenzen der Europäischen Union nicht ausweiten soll. Mit Blick auf die Organkompetenzen ist die Initiative deshalb nur zulässig im Zuständigkeitsbereich der Kommission und mit Blick auf die Verbandskompetenzen zudem nur zur Umsetzung der Verträge. Darüber hinaus entfaltet die Initiative gegenüber der Kommission kaum eine verbindliche Wirkung. Primärrechtlich jedenfalls ist weder in Art. 11 Abs. 4 EUV noch in Art. 24 Abs. 2 AEUV festgelegt, ob die Kommission überhaupt tätig werden muss und gegebenenfalls wie. Die Bindungswirkung einer Unionsbürgerinitiative wird insofern vor allem faktischer Natur sein und maßgeblich von der erzeugten öffentlichen Meinung abhängen. In ihren konkreten Auswirkungen wird dieses Instrument - so bedeutsam es zunächst erscheinen mag wohl lediglich mit der konzertierten Petition auf nationaler Ebene vergleichbar sein.

\section{Petitionsrechte}

Damit ist ein zweites normativ ausgestaltetes Instrument angesprochen. mit dem Bürger auf allen staatlichen Ebenen die staatliche Gesetzgebung zu beeinflussen versuchen können: das Petitionsrecht.

\section{a) Petitionsrechte auf Bundes- und Landesebene}

Das Petitionsrecht ist auf Bundes- und Landesebene weitgehend gleich ausgestaltet, so dass dieser Überblick sich exemplarisch auf die Bundesebene beschränkt.

Nach Art. 17 GG hat jedermann das Recht, sich einzeln oder in Gemeinschaft mit anderen schriftlich mit Bitten oder Beschwerden an die zuständigen Stellen und an die Volksvertretung zu wenden. Zuständige Stelle und Adressat ist der 
nach Art. 45c GG eingerichtete Petitionsausschuss des Deutschen Bundestages. Der Petitionsausschuss vertritt in seinem Zuständigkeitsbereich das Plenum. ${ }^{10}$

Die Arbeitsweise des Petitionsausschusses ist im Gesetz über die Arbeitsweise des Petitionsausschusses des Deutschen Bundestages in $\$$ \$ $108 \mathrm{ff}$. GOBT und in den auf Grundlage des $\S 110$ GOBT erlassenen verwaltungsmäßigen Anweisungen $^{11}$, den sog. Grundsätzen des Petitionsausschusses zur Behandlung von Bitten und Beschwerden, näher geregelt. Regelmäßig erstellt der Petitionsausschuss eine Sammelübersicht der Petitionen für die Mitglieder des Parlaments und übergibt diese monatlich mit Beschlussempfehlungen ( $\$ 112$ GOBT). Wird eine Petition innerhalb von drei Wochen von mindestens 50.000 Menschen unterstützt, wird die Petition öffentlich im Petitionsausschuss beraten und dem Petenten ein Rederecht eingeräumt. Grundsätzlich hat der Petent jedoch nur einen Anspruch auf Entgegennahme und Bescheidung der Petition, nicht jedoch auf eine Begründung.

Die Bedeutung einer Petition ist nicht zu unterschätzen. Das gilt schon bei theoretischer Betrachtung, weil das Petitionsrecht eng mit dem Demokratieprinzip verbunden ist. Das gilt aber auch bei praktischer Betrachtung, denn hier lässt sich die Petition - unabhängig von ihrem konkret-individuellen Erfolg - durchaus auch als Kommunikationsmittel zwischen dem Parlament und den Bürgern begreifen: Die Petition ist die einzige (formalisierte) Möglichkeit des Bürgers, sich direkt an den Gesetzgeber zu wenden. Förmliche Rechtsbehelfe gehen dagegen den Weg rückwărts, den ein parlamentarischer Gesetzesbefehl über seinen konkreten Vollzug bis hin zur gerichtlichen Überprüfung nimmt, und werden vom Parlament nicht mehr in erster Linie als Beschwerde von Bürgern, sondern als Entscheidungen der Gerichte und d.h. einer anderen staatlichen Gewalt empfunden. Im Übrigen wird regelmälig darauf hingewiesen, dass Petitionen statistisch gesehen erfolgreicher sind als Verfassungsbeschwerden. Hinter der Relativität dieser Aussage verbergen sich bei absoluter Betrachtung freilich recht geringe Erfolgsaussichten von Petitionen. Sie erhöhen sich erst dann, wenn sie von möglichst vielen Bürgem eingereicht werden. Dies erfordert allerdings bereits eine besondere Organisation des Interesses, die dann eher in anderen Formen politischer Willensbildung, insbesondere in politischen Parteien oder anderen Gruppierungen, kanalisiert wird.

10 Vgl. Wolfgang Graf Vitzthum/Wolfgang März, Der Petitionsausschuss, in: Hans-Peter Schneider/Wolfgang Zeh (Hrsg.), Parlamentsrecht und Parlanentspraxis, 1989, \$ 45 Rn. 3.

11 Wolfgang Graf Vitzthum/Wolfgang Mörz, Der Petitionsausschuss, in: Hans-Peter Schneider/Wolfgang Zeh (Hrsg.), Parlamentsrecht und Parlantentspraxis, 1989, $\$ 45$ Rn. 4. 


\section{b) Petitionsrecht auf Ebene der Europäischen Union}

Auch auf europäischer Ebene hat der Bürger allein oder in einer konzertierten Aktion bereits seit der Gründung der Europäischen Union durch den Vertrag von Maastricht und der mit ihm eingeführten Unionsbürgerschaft nach den heutigen Art. 20 Abs. 2 lit. d AEUV und Art. 227 AEUV die Möglichkeit, sich mit einer Petition an das Europäische Parlament zu wenden. Inhaltlich ist diese Möglichkeit auf den Kompetenzrahmen der Europäischen Union bzw. auf die Bereiche, die die Union unmittelbar betreffen, beschränkt. Petitionen können schriftlich oder per Internet eingereicht werden. Der Aussteller muss erkennbar und die Petition unterschrieben sein. Es gibt unterschiedliche Behandlungsmöglichkeiten für eine zulässige Petition. Unter anderem kann eine Weiterleitung an andere Ausschüsse erfolgen, eine vorläufige Prüfung der Petition durch die Kommission veranlasst oder ein Bericht ausgearbeitet und dem Plenum zur Abstimmung vorgelegt werden.

Wie bei der Ausgestaltung des nationalen Petitionsrechts ist Adressat der Petition auf europäischer Ebene das Parlament. Dies schwächt die Bedeutung des Petitionsrechts insofern, als das Europäische Parlament anders als die nationalen Parlamente nicht befugt ist, Rechtsakte zu initiieren. Mit der zunehmenden Bedeutung des Europäischen Parlaments und seiner kontinuierlichen Aufwertung im Rechtsetzungsverfahren durch die Verträge von Maastricht, Amsterdam, Nizza und Lissabon hat aber auch das Petitionsrecht an Bedeutung gewonnen, insbesondere, wenn man es weniger als ein Instrument zur Durchsetzung individueller Interessen als vielmehr als ein Kommunikationsmittel zwischen dem Europäischen Parlament und den europäischen Bürgern versteht - ein Instrument, das auf europäischer wie auf nationaler Ebene dazu gedacht ist, den rechtsunterworfenen Privaten mit einer Rückmelde- zugleich auch eine Einflussmöglichkeit auf die hoheitliche Rechtsetzung einzuräumen.

\section{Akteure}

Die skizzierten Schnittstellen zwischen staatlicher Gesetzgebung und nichtstaatlichen Einflussmöglichkeiten knüpfen in ihrer demokratischen Verbundenheit an den Bürger an. Der Bürger handelt auch in einer individualistisch konzipierten Freiheitsordnung aber regelmäßig nicht für sich alleine, sondern artikuliert seine Interessen zusammen mit anderen und in unterschiedlichsten Organisationsformen. Einfluss auf die staatliche Gesetzgebung versuchen etwa politische Parteien (1.), Verbände jeder Art (2.), insbesondere auch Gewerkschaften und Arbeitgeberverbände (3.), Kirchen (4.) und Unternehmen (5.) auszuüben. Verstärkt treten spezialisierte Agenturen (6.) und kurzfristige Zusammenschlüsse (7.) auf. Darü- 
ber hinaus nehmen die verschiedensten Gremien und Beiräte (8.) Einfluss auf die staatliche Gesetzgebung. Hervorgehoben sei der Gemeinsame Bundesausschuss mit seinen weitgehenden Befugnissen im Gesundheitswesen (9.). Besonders wirkmächtig ist darüber hinaus die in den Medien artikulierte öffentliche Meinung (10.).

\section{Politische Parteien}

Prädestiniert für den nichtstaatlichen Einfluss auf die staatliche Gesetzgebung sind die politischen Parteien, die zugleich im gesellschaftlichen Bereich verwurzelt sind und in den staatlichen Organen wirken. Bereits nach ihrer gesetzlichen Definition in $\S 2$ Abs. 1 S. 1 PartG zielen Parteien als Vereinigungen von Bürgern dauerhaft oder jedenfalls längerfristig darauf, die politische Willensbildung in einem Land oder im Bund zu beeinflussen und an der Vertretung des Volkes im Bundestag oder einem Landtag mitzuwirken. Die Mitwirkung bei der politischen Willensbildung des Volkes in den Parlamenten ist dabei nicht nur konstitutive Voraussetzung einer politischen Partei, sondern zugleich auch Verfassungsauftrag und Grund für eine Reihe verfassungsrechtlicher Privilegien. Ob die Willensbildung in den einzelnen politischen Parteien dabei stets von unten nach oben erfolgt, wie es das Verfassungsgebot demokratischer Binnenordnung in Art. 21 Abs. 1 S. 3 GG in Idealisierung demokratietheoretischer Überlegungen verlangt, mag unterschiedlich beurteilt werden. ${ }^{12}$ Entscheidend ist die Verwurzelung der politischen Parteien in der Gesellschaft bei gleichzeitiger Intention, in den Parlamenten an der staatlichen Entscheidungsfindung mitzuwirken. Außerdem unterscheiden sich die politischen Parteien dadurch von anderen Formen des nichtstaatlichen Einflusses auf die staatliche Gesetzgebung, dass sie regelmäßig alle Politikbereiche zu beeinflussen suchen und nicht, wie etwa die Verbände, auf bestimmte Themen beschränkt sind.

\section{Verbände}

Neben den politischen Parteien kann die Arbeit der Verbände fast schon klassische Art des organisierten Einflusses auf die staatliche Gesetzgebung angesehen

12 Vgl. dazu Marthias Rossi, Möglichkeiten der rechtlichen Absicherung der innerparteilichen Willensbildung, in: Ulrich von Alemann/Martin Morlok/Julian Krüper (Hrsg.), (Partei-)Politik im Zeichen des Marketing, 2010, S. 79 ff. 
werden. ${ }^{13}$ Zwar lässt sich der Begriff Verband nicht abschließend griffig definieren. Allerdings kann er mit einigen Merkmalen umschrieben werden. Es handelt sich um eine „nicht-staatliche, von mehreren Personen, Gruppen oder Unternehmen mit gleichgerichteten Interessen gebildete Vereinigung" mit einem gewissen Organisationsgrad, die eine ,gewisse Beständigkeit aufweist, auf deren Grundlage ihre Leitungspersonen zur Interessenvertretung nach außen politisch aktiv sind“. Verlangt wird darüber hinaus eine gewisse politische Relevanz. ${ }^{14}$ Öffentlich-rechtlichen Körperschaften wie Berufskammern fehlt es an der Freiwilligkeit des Zusammenschlusses, so dass sie jedenfalls formal nicht den Verbänden zugeordnet werden können. zumal sie auch noch öffentlich-rechtlich organisiert sind. Funktional lassen sie sich gleichwohl im Kontext der nichtstaatlichen Beeinflussung der staatlichen Gesetzgebung durchaus mit den Verbänden vergleichen.

Die Arbeit der Verbände ist dadurch gekennzeichnet, dass sie jeweils nur einen Teil der Gesellschaft und damit nur ein partikulares Gruppeninteresse vertreten. Von den vielfältigen Möglichkeiten, dieses partikulare Gruppeninteresse in die staatliche Gesetzgebung einfließen zu lassen, sei nur ein formalisiertes Instrument hervorgehoben: Nach $\$ 47$ Abs. 3 GGO sind die Zentral- und Gesamtverbände frühzeitig über Gesetzentwürfe zu informieren, deren Unterstützung nach $\S 44$ Abs. 4 GGO zudem für die Ermittlung der Gesetzesfolgen benötigt wird.

\section{Gewerkschaften, Arbeitgeberverbände}

Unter den Verbänden nehmen die Gewerkschaften und Arbeitgeberverbände eine hervorgehobene Stellung hinsichtlich der Beeinflussung der staatlichen Gesetzgebung ein, die grundrechtlich von Art. 9 Abs. 3 GG unterstrichen wird. Denn dic Arbeit der Sozialpartner ist nicht nur auf die Lohnfindung beschränkt, sondern auch auf die sonstigen Arbeits- und Sozialbedingungen gerichtet und versucht also, das Arbeits- und Sozialrecht zu beeinflussen. Umgekehrt hat auch der Staat ein Interesse an einer Kooperation, jedenfalls aber einer Kommunikation mit den Sozialpartnern, weil die privatautonom vereinbarten Tarife durchaus gesamtwirtschaftliche Folgen hervorrufen.

13 Schon früh wurde der Einfluss der Verbände untersucht. sodass Theodor Eschenburg 1956 im Titel seines Werkes fragte: „Herrschaft der Verbände?” (Stuttgart).

14 Hierzu und zum Folgenden Hans-Detlef Horn, Verbände, in: Josef Isensee/Paul Kirchhof (Hrsg.), Handbuch des Staatsrechts, Band III, 3. Auflage 2005, \$ 4 I Rn. 5 ff. 


\section{Kirchen}

Ähnlich verhält es sich mit den Kirchen, allen voran mit den beiden großen als Körperschaften des öffentlichen Rechts organisierten christlichen Kirchen, die durch diese Organisationsform von dem bewusst konservativen und konservierenden Charakter des Art. 137 WRV gegenüber anderen Religionsgesellschaften privilegiert werden. Auch sie nehmen nicht nur auf die sie unmittelbar betreffende staatskirchenrechtliche Gesetzgebung Einfluss, sondern beziehen Stellung zu vielen Fragen insbesondere moralischer oder ethischer Natur, wie die Diskussionen über die strafrechtliche Behandlung der Abtreibung oder über die Humangenetik beispielhaft belegen mögen. Die Kirchen nutzen dabei vielfältige Instrumente, um ihren Einfluss auf die staatliche Gesetzgebung auszuüben. Die unmittelbare Einbindung der Institution Kirche als solcher in das staatliche Gesetzgebungsverfahren ist dabei nur eine Erscheinungsform. Gewichtiger dürfte der Einfluss der Kirchen sein, wo es ihnen gelingt, Personen und Positionen der politischen Parteien zu bestimmen.

\section{Unternehmen}

Als weitere Akteure des nichtstaatlichen Einflusses kommen vornehmlich große Unternehmen in Betracht, die durch eine geschickte Einflussnahme auf die Gesetzgebung vor allem die wirtschaftlichen Grundbedingungen ihres Handelns zu beeinflussen versuchen ${ }^{15}$ Regelmäßig werden sie ihr Ziel zwar über Verbände oder Kammern verfolgen, weil dies in vielen Fällen ökonomischer und wirkmächtiger ist. Außerdem kann ein möglicher Imageschaden beim Verbraucher vermieden werden, wenn die Interessen allgemein bekannter Untemehmen hinter den Interessen regelmäßig unbekannter Verbände versteckt werden. Allerdings können đurchaus Anreize für Unternehmen bestehen, selbst und unmittelbar zu handeln, etwa wenn es von der übergeordneten Einheit abweichende Ziele verfolgt, spezielle Partikularinteressen durchsetzen möchte oder sich von seiner Einmischung ausschließlich ein positives Echo in den Medien und damit bei den Verbrauchern erhofft.

15 Hierzu siehe Klaus Escher, Unternehmenslobbying. Studie zur politischen Kommunikation der BASF und Gottlob Schober, Die Deutsche Telekom. Lobbyarbeit fuir den Börsengang, jeweils in: Thomas Leif/Rudolf Speth (Hrsg.), Die Stille Macht. Lobbyismus in Deulschland, Wiesbaden 2003, S. 98 ff. und $157 \mathrm{ff}$. 


\section{Spezialisierte Agenturen}

Vermehrt bedienen sich Unternehmen in solchen Fällen allerdings spezialisierten Agenturen, die sich „Public Affairs“" widmen und sich deshalb unter dem Begriff „PA-Agenturen“ zusammenfassen lassen.

"Public Affairs (PA) bezeichnet das strategische Management von Entscheidungsprozessen an der Schnittstelle zwischen Politik. Wirtschaft und Gesellschaft."16 Überschneidungen mit den Begriffen ,Public Relations“ und „Lobbying sind ohne weiteres erkennbar. ${ }^{17}$ Der Ansatz von PA-Agenturen geht aber über diese fast schon tradierten Formen der Einflussnahme hinaus, er zielt auf die Beeinflussung sämtlicher Entscheidungsprozesse im Sinne der handelnden Organisation. ${ }^{18}$ Die Public Affairs betreibenden Organisationen oder Unternehmen bewegen sich dabei nicht nur im bipolaren Verhältnis zum Entscheidungsträger wie z.B. dem Parlament. Vielmehr haben ihre Interessen regelmäßig Auswirkungen auf andere Anspruchsgruppen (sogenannte Stakeholder). die möglicherweise entgegengesetzte Interessen verfolgen. ${ }^{19} \mathrm{Im}$ Wege der Public Affairs sollen die Interessen auch gegenüber diesen Stakeholdern durchgesetzt werden.

Der Trend, Public Affairs nicht nur durch Einzelberater und kommerzielle Lobbyisten, durch PR-Agenturen, Unternehmensberatungen oder Anwaltskanzleien, durch Unternehmensverbände wie den BDI oder durch Konzern- und Unternehmensrepräsentanzen ${ }^{20}$ auszuüben, sondern verstärkt spezialisierte PA-Agenturen einzusetzen, ist vor allem auf europäischer Ebene zu verzeichnen. Hier haben „Public Affairs“ eine weit größere Bedeutung als auf nationaler oder gar regionaler Ebene ${ }^{21}$, die mit jeder weiteren Übertragung von Rechtsetzungskompetenzen

16 Wikipedia.org. Eintrag ..Public Affairs“, abgerufen am I1.06.2010.

17 Rolf Steltemeier/Matthias Catón, in: Nohlen/Grotz (Hrsg.), Kleines Lexikon der Politik, 4. Aufl. 2007, S. 457.

18 Rolf Steltemeier/Matthias Carón, in: Nohlen/Grotz (Hrsg.). Kleines Lexikon der Politik, 4. Aufl. 2007, S. 457.

19 Peter Köppl, in: Althaus/Geffken/Rabe (Hrsg.), Handlexikon Public Affairs, 2005, S. 13.

20 Rolf Stehemeier/Matthias Catón, in: Nohlen/Grotz (Hrsg.). Kleines Lexikon der Politik, 4. Aufl. 2007, S. 458.

21 Einen Überblick bieten Tobias Kahler/Manuel Lianos, Neue Aktionsfelder: Agenturen in den Lobby-Kinderschuhen, in: Thomas Leif/Rudolf Speth (Hrsg.). Die Stille Macht. Lobbyismus in Deutschland, Wiesbaden 2003, S. 355 ff. und André Chahoud, Blicke hinter die Kulissen: Aus dem "Alltag" eines Politikberaters. APuZ 19/2010, S. 34 ff. Siehe femer Julien Amaud. Die Mitwirkung privater Interessengruppen an der europäischen Gesetzgebung. Aachen 2009 (Dissertation); ein Vergleich mit der Lobby-Landschaft in den USA findet sich bei Eike Krafi. Lobbying in der EU. Regulierung nach US-Vorbild?. Saarbrücken 2006. 
auf die Europäische Union weiter gestiegen ist. ${ }^{22}$ Derzeit sind in Brüssel ca. 143 kommerzielle Beratungsfirmen und 125 dieser Rechtsanwaltskanzleien ${ }^{23}$ angesiedelt. Die große Konkurrenz hat zu einem „Aufrüsten“ der Branche geführt, so dass sich die Verbände professionalisieren und vermehrt Fachkenntnisse anhäufen. ${ }^{24}$ Die Anforderungen an Interessenvertreter bei der EU sind aufgrund des permanenten Wandels auf europäischer Ebene sowieso sehr hoch und erfordern Flexibilität und eine gute Kenntnis der Institutionen sowie der Entscheidungsabläufe auf europäischer Ebene. ${ }^{25}$

\section{Kurzfristige Zusammenschlüsse}

Ganz im Gegensatz zu den immer stärker organisierten und umfassend agierenden PA-Agenturen stehen kurzfristige Zusammenschlüsse, die mitunter versuchen, die staatliche Gesetzgebung zu beeinflussen, etwa durch entsprechende Meinungskundgaben auf Demonstrationen. Je weniger organisiert und je sachbzw. ereignisbezogener sie agieren, desto eher werden sie freilich nur als Protestbewegung wahrgenommen, der es mehr darum geht, ein bestimmtes Gesetzesprojekt vollständig zu verhindern als es inhaltlich zu beeinflussen. Je mehr sie dagegen nicht nur destruktiv, sondern konstruktiv auf ein Gesetzesvorhaben einwirken wollen, desto eher werden sie einen höheren Organisationsgrad erreichen und in die Rolle anderer Akteure schlüpfen oder sich solcher bedienen. Wenn sie in diesem Panoptikum gleichwohl als eigener Akteur behandelt werden, dann deshalb, weil es mit den zunehmend vereinfachten Kommunikationsmöglichkeiten à la twitter etc. durchaus möglich erscheint, die Interessen einzelner auch ohne strenge Organisation zu einem Schwarm zu bündeln. der als solcher wirkmächtiger ist als jedes in ihm ebenso auf- wie untergehendes Individuum.

22 Werner P. Bohrer/Sven Rawe, in: Althaus/Geffken/Rabe (Hrsg.), Handlexikon Public Affairs, 2005, S.180.

23 Hans-Jörg Schmedes, Das Mosaik der Interessenvermittlung im Mehrebenensystem Europas, APuZ 19/2010, S. 22 unter Verweis auf Simon Hix, The Political System of the European Union, 2005, S. 212.

24 Michael Kambeck, in: Dagger/ders.(Hrsg.), Politikberatung und Lobbying in Brüssel, 2007 , S. 258 f.

25 Werner P. Bohrer/Sven Rawe, in: Althaus/Geffken/Rabe (Hrsg.), Handlexikon Public Affairs, 2005, S.180. 


\section{Gremien, Bciräte und Räte}

Ganz anders verhält es sich wiederum mit den zahlreichen Gremien und Beiräten, die bei staatlichen Stellen, namentlich bei den Ministerien, angesiedelt sind und von vomeherein den Zweck haben, außerstaatlichen Sachverstand in dic staatliche Gesetzgebung einzubeziehen. In einer jüngeren Untersuchung des wissenschaftlichen Dienstes des Bundestages werden insgesamt 94 solcher Beratungsgremien vorgestellt. ${ }^{26}$ Hinsichtlich des tatsächlichen Einflusses dieser Gremien, Beiräte und Räte muss wohl grundsätzlich betont werden, dass sie beratend, nicht entscheidend tätig werden, darüber hinaus aber sicherlich nach den einzelnen Gremien differenziert werden. Gemeinsam ist ihnen allerdings, dass sie primär darauf gerichtet sind, Sachverstand in die Gesetzgebungsarbeit einzubringen. Dass die Abgrenzung von Sachverstand, gar vielleicht wissenschaftlichem Sachverstand, zu bloßen Interessenvertretungen schwierig ist, wird man nur bei sehr naiver oder sehr idealistischer Betrachtungsweise leugnen können. Viele wichtige politische Entscheidungen werden gerne wissenschaftlich begründet und ausgeflaggt, obwohl die Wissenschaft selbst doch viele Alternativen bereit hielte und sich die politische Entscheidung also nicht als alternativloses Ergebnis wissenschaftlicher, also vermeintlich objektiver Zwänge ergibt. Das gilt in ganz besonderem Maße für die Wirtschaftswissenschaften. Doch unabhängig von solchen Vorbehalten gegenüber der Arbeit dieser Gremien ist für ihre Erwähnung im Rahmen dieses Panoptikums entscheidend, dass in ihnen Personen wirken, die nicht unmittelbar dem Staat zugerechnet werden können. Insofern handelt es sich bei diesen Gremien trotz ihrer Anbindung an die Regierungsoder gar an die Legislativorgane um Erscheinungsformen nichtstaatlicher Einflüsse auf die staatliche Gesetzgebung.

\section{Gemeinsamer Bundesausschuss}

Eine besondere Rolle nimmt der Gemeinsame Bundesausschuss ein, der als Gremium und oberstes Beschlussorgan der Ärzte, Zahnärzte, Psychotherapeuten. Krankenhäuser und Krankenkassen ${ }^{27}$ die vertragsärztliche Versorgung sowie die Krankenhausversorgung maßgeblich beeinflusst.

Zwar mag schon aus zwei formalen Gründen heraus bezweifelt werden, dass er im Rahmen dieses Panoptikums von Erscheinungsformen nichtstaatlicher Ein-

26 Birgit Schröder, Beratungsgremien bei der Bundesregierung und beim Bundestag. http:// www.bundestag.de/dokumente/analysen/2010/Beratungsgremien.pdf.

27 Schmidt-De Calıwe, in: Becker/Kingreen, SGB V, 2. Aufl. 2010, §91 Rn. 1. 
flüsse auf die staatliche Gesetzgebung Erwähnung finden sollte. Erstens nämlich ist er nach $\$ 91$ Abs. 1 Satz 2 SGB V als juristische Person des öffentlichen Rechts ausgestaltet und untersteht zudem der Rechtsaufsicht des Bundesministeriums für Gesundheit, ${ }^{28}$ so dass er nicht ohne weiteres der nichtstaatlichen SphäTe zuzurechnen ist. Und zweitens ist er nur zum Erlass von „Richtlinien“ berufen, denen normalerweise keine verbindliche Außenwirkung zukommt.

Bei materieller Betrachtung zeigt sich allerdings, dass dem Gemeinsamen Bundesausschuss sehr wohl ein gebührender Ausstellungsplatz in diesem Panoptikum der unterschiedlichsten Erscheinungsformen nichtstaatlicher Einflussnahme auf die staatliche Gesetzgebung gebührt. Schon die gesetzlich zugewiesene Hauptaufgabe indiziert die Bedeutung des Gemeinsamen Bundesausschusses: Nach \$ 92 Abs. 1 S. 1 SGB V soll der Gemeinsame Bundesausschuss die zur Sicherung der ärztlichen Versorgung erforderlichen Richtlinien über die Gewähr für eine ausreichende, zweckmäßige und wirtschaftliche Versorgung der Versicherten beschließen. Dahinter verbirgt sich aber nicht mehr und nicht weniger als die Befugnis, über die Finanzierung und d.h. häufig über die Durchführung oder Versagung der medizinischen Leistungen zu entscheiden. Grundlage der Entscheidung sind dabei der medizinische Nutzen einer Leistung ebenso wie deren Wirtschaftlichkeit. ${ }^{29}$ Neben dieser Generalklausel enthält $\$ 92$ Abs. 1 S. 2 SGB $V$ einen nichtabschließenden Katalog von Sachgebieten, für die der Gemeinsame Bundesausschuss ebenfalls Richtlinien erlassen soll. Diese Soll-Anforderung verdichtet sich zu einer Pflicht, wenn zur Sicherstellung der wirtschaftlichen Versorgung der Versicherten eine Regelung notwendig ist. ${ }^{30}$

Die besondere Bedeutung des Gemeinsamen Bundesausschusses resultiert dabei aus der besonderen Wirkung der von ihm erlassenen Richtlinien. Sie sind nach \$91 Abs. 6 SGB V sowohl für die Träger des Gemeinsamen Bundesausschusses und deren Mitglieder und Mitgliedskassen als auch für die Versicherten und die Leistungserbringer verbindlich. Da die Versicherten aber nicht zu den Körperschaften gehören, die im Gemeirisamen Bundesausschuss zusammengeschlossen sind, ist die Grenze des auf die Mitglieder beschränkten Satzungsrechts überschritten. Vor diesem Hintergrund kommt den Richtlinien also Außenwirkung zu, wie auch immer sie formal qualifiziert werden. Zum Teil werden sie als materielle Gesetze verstanden, die Elemente der delegierten Rechtsetzung und des

Näher Reiner Hess, in: Kasseler Kommentar, Sozialversicherungsrecht, 67. EL 2010, \$91 Rn. 3.

29 Dontrik Roters, in: Kasseler Kommentar, Sozialversicherungstecht, 67. EL 2010, § 92 Rn. 4,6.

30 BSG, MedR 1988, 230, 235. 
autonomen Satzungsrechts verbinden, ${ }^{31}$ zum anderen werden sie als abstraktgenerelle Verwaltungsvorschriften qualifiziert, die über das Gleichbehandlungsgebot des Art. 3 Abs. 1 GG Bindungswirkung entfalten können. ${ }^{32}$ Freilich erlangen die Richtlinien nach $\S 94$ Abs. 1 SGB V erst Wirksamkeit, wenn das Bundesministerium für Gesundheit keine Beanstandung vorgenommen hat. Nach § 94 I 4 SGB V kann das Ministerium die Nichtbeanstandung auch mit Auflagen versehen, es hat also die Möglichkeit, noch inhaltlichen Einfluss auf die Richtlinien zu nehmen, ohne diese gleich zu beanstanden. Formal bleibt das Entscheidungsrecht somit beim staatlichen Ministerium, faktisch ist es allerdings dem Gemeinsamen Bundesausschuss übertragen. Dies wiegt umso schwerer, als der Bundesausschuss auch in anderen gesundheitspolitischen Bereichen weitreichende Entscheidungen treffen kann. Die von § 35a SGB V normierte Aufgabe, den Nutzen von Arzneimitteln mit neuen Wirkstoffen zu prüfen, kann schnell im Sinne der Befugnis, über die Zulassung neuer Arzneimittel zu entscheiden, ausgeübt werden.

Die geschilderten Aufgaben und ihre Ausübung lassen den Bezug zur staatlichen Gesetzgebung vielleicht nicht auf den ersten Blick erkennen. Allerdings sei in Erinnerung gerufen, dass auch der Erlass von Rechtsverordnungen unter die staatliche Gesetzgebung subsumiert werden muss, und vor diescm Hintergrund sind die Aufgaben des Gemeinsamen Bundesausschusses ausgesprochen weitreichend. Insofern sei abschließend noch einmal die Besetzung des Gemeinsamen Bundesausschusses vor Augen geführt. Er wird nach §9l Abs. I S. 1 SGB V durch die kassenärztlichen Bundesvereinigungen, die Deutsche Krankenhausgesellschaft und den Spitzenverband Bund der Krankenkassen gebildet und besteht nach $\S 91$ Abs. 2 S. 1 SGB V aus insgesamt 13 Mitgliedem: Dem unparteiischen Vorsitzenden, zwei weiteren unparteiischen Mitgliedern sowie fünf Vertretern des Spitzenverbandes Bund der Krankenkassen, einem Vertreter der Kassenzahnärztlichen Bundesvereinigung und jeweils zwei Vertretern der Kassenärztlichen Bundesvereinigung und der Deutschen Krankenhausgesellschaft. Die Mitwirkung anerkannter Bundesorganisationen der Patientinnen und Patienten und der Selbsthilfe chronisch kranker und behinderter Menschen ist in $\S 91$ Abs. 2 SGB V nicht vorgesehen. Allerdings können diese anerkannten Interessenvertretungen von Patienten nach $\S 140$ f Abs. 2 SGB V sachkundige Personen benennen, die im Gemeinsamen Bundesausschuss ein Mitberatungsrecht haben. Dieses Mitberatungsrecht beinhaltet ein Anwesenheits- und Rederecht in den Sitzungen

31 Hans-Dieter Sproll, in: Krauskopf. Soziale Krankenversicherung. Pflegeversicherung. 71. EL 2010. $\$ 92$ Rn. 8 ff.

32 Raimund Schmidt-De Caluwe, in: Becker/Kingreen, SGB V, 2. Aufl. 2010, §92 Rn. 14. 
des GB-A sowie ein vollständiges Informationsrecht, nicht jedoch ein Antragsoder Stimmrecht. ${ }^{33}$

\section{0. Öffentliche Meinung und Medien}

Ein abschließender Blick soll auf die öffentliche Meinung gerichtet werden, die vor allem durch die Medien, allen voran den Massenmedien, erzeugt wie wiedergegeben wird. Eine seriöse und wissenschaftlich belastbare Betrachtung der Wechselwirkung zwischen staatlicher Gesetzgebung auf der einen Seite und der öffentlichen Meinung und den Medien auf der anderen Seite kann dabei allerdings nicht vorgenommen werden. Vielmehr soll nur die Besonderheit hervorgehoben werden, dass sowohl die öffentliche Mcinung ${ }^{34}$ wie auch dic Medien ${ }^{35}$ in viełfältigen und verschiedenen Rollen in dieses Wirkgefüge eingebunden sind. Sie lassen sich einerseits den Akteuren zurechnen, andererseits aber auch als Adressaten (anderer Akteure) begreifen und sind schließlich zugleich auch Instrument der Einflussnahme.

\section{Adressaten}

Damit soll die Perspektive gewechselt werden, aus der die Erscheinungsformen nichtstaatlicher Einflussse auf die staatliche Gesetzgebung betrachtet werden. Wenn im Folgenden die Adressaten dieser Einflussnahme im Vordergrund stehen, soll der Frage nachgegangen werden, wer eigentlich beeinflusst werden soll. Dabei wird hier ausgeklammert, dass der Einfluss häufig sehr mittelbar ausgeübt wird, indem ein Akteur einen anderen als Adressaten betrachtet. Insbesondere die politischen Parteien und die Medien lassen sich insofern nicht trennscharf der einen oder anderen Gruppe zuordnen. Vielmehr fuggieren sowohl die politischen Parteien als auch die Medien als Mittler, um nichtstaatliche Interessen und Vorstellungen in die staatlichen Organe zu tragen.

Diese vielfachen Wechselwirkungen können hier nicht betrachtet werden. Vielmehr werden als Adressaten nur die staatlichen Organe in das Rampenlicht ge-

33 Jurla Kaempfe, in: Becker/Kingreen, SGB V, 2. Aufl. 2010, \$ 104f Rn. 6.

$34 \mathrm{Zu}$ möglichen Definitionsversuchen und Begriffsmerkmalen siehe ebenfalls Michael Kloepfer, Öffentliche Meinung, Massenmedien, in: Josef Isensee/Paul Kirclihof (Hrsg.), Handbuch des Staatsrechts, Band 11I, 3. Auflage 2005, § 42 Rn. 1 ff.

35 Michael Kloepfer, Öfentliche Meinung, Massenmedien, in: Josef Isensee/Paul Kirchhof (Hrsg.), Handbuch des Staatsrechts, Band III. 3. Auflage 2005, $\$ 42$ Rn. 7 mil weiteren Erläuterungen. 
rückt. Im Vordergrund stehen dabei zunächst die Legislativorgane mit ihrer Befugnis, die materiellen Gesetze zu verabschieden (1.). Weil deren Inhalt aber zumeist schon durch die gesetzesvorbereitende Ministerialverwaltung erarbeitet wird, stehen auch die Regierungen im Fokus der verschiedenen Akteure. Dies gilt wegen des weitgehenden Initiativmonopols der Europäischen Kommission für die Europäische Union in besonderem Maße (2.). Allein die rechtsprechende Gewalt ist nicht primärer Adressat nichtstaatlichen Einflusses auf die staatliche Gesetzgebung, weil sie in der Regel nur geringfügige Korrekturen an bereits in Kraft befindlichen Gesetzen ausüben kann (3.).

\section{Legislativorgane}

Von den Legislativorganen auf Bundesebene ist der Bundestag gegenüber dem Bundesrat der primäre Adressat von Einflussversuchen. Dies lässt sich ohne weiteres damit begründen, dass der Bundestagsbeschluss nach Art. 77 Abs. 1 GG stets notwendige Voraussetzung für das Inkrafttreten eines Bundesgesetzes ist. während der Bundesrat insbesondere bei Einspruchsgesetzen kaum noch Einfluss auf den Inhalt des Gesetzes nehmen kann. Bei Zustimmungsgesetzen sowie insbesondere bei anderer parteipolitischer Zusammensetzung des Bundesrates kann aber auch einmal der Bundesrat primäres Ziel von Einflussnahmeversuchen sein, ebenso natürlich auch bei (zustimmungsbedürftigen) Rechtsverordnungen.

Innerhalb des Bundestages ist es selten das Plenum, das in seinem Abstimmungsverhalten gesteuert werden soll. Denn die Abstimmungen stehen naturgemäß erst am Ende des gesetzgeberischen Entscheidungsprozesses. Auch die vorgeschaltete erste und zweite Lesung von Gesetzentwürfen im Plenum ist nicht der wirkungsvollste Ort, um inhaltliche Beeinflussungen vorzunehmen. Im Vordergrund stehen vielmehr einzelne Abgeordnete sowie namentlich die jeweiligen Fachausschüsse, in denen eine Anhörung von Privaten zum Teil sogar formalisiert und eine schriftliche Einbringung darüber hinaus stets möglich ist. Auf "Lobbying" und andere Formen der Interesseneinbringung spezialisierte Akteure wissen stets um das konkrete Gesetzgebungsverfahren, wissen um den federführenden Ausschuss, seine Vorsitzenden und seine Mitglieder, wissen um die anderen beteiligten Ausschüsse und nutzen jede dieser möglichen Stellschrauben, um das Ergebnis dieses legislativen Räderwerks zu ihren Gunsten zu beeinflussen. Freilich wird dabei sehr oft wohl auch Öl an Stellen geschmiert, die für das Gesamtergebnis völlig bedeutungslos sind. 


\section{Exekutivorgane}

Die Legislatjvorgane mit iłren Untergliederungen stellen aber nur eine mögliche Adressatengruppe dar. Die Interessenträger haben längst die Entwicklung des deutschen Parlamentarismus erkannt, die immer öfter unter dem Begriff der Entparlamentarisierung diskutiert wird. ${ }^{36}$ Mit diesem Begriff soll der Bedeutungsverlust des Bundestags als Entscheidungsträger im Gesetzgebungsverfahren beschrieben werden, der seinerseits vielfältige Ursachen hat. Neben einer Verlagerung von materiellen Entscheidungskompetenzen auf die Ebene der Europäischen Union rüht dieser Bedeutungsverlust jedenfalls auch aus der Auslagerung der Entscheidungsprozesse in die Ausschüsse und vor alkem auf die Exekutivebene in Form der einzelnen Ministerien her. Fakt ist, dass die meisten der Gesetzentwürfe nicht „aus der Mitte des Bundestages" oder vom Bundesrat eingebracht werden, sondern von der Bundesregierung. Sie verfügt in ihren Ministerien über das nötige Personal und den erforderlichen Sachverstand, urn die Gesetze hinreichend schnell und entsprechend den rechtstaatlichen Anforderungen vorzubereiten. ${ }^{37}$ Die Interessenträger haben exkannt, dass eine frühe Einflussnahme in diesem Stadium der legistischen Arbeit weit wirksamer ist als der Versuch der Einflussnahme im Parlament, wenn die wichtigsten Entscheidungen längst getroffen sind.

Mit Blick auf die Gesetzgebung des Bundes steht dabei zunächst die Ministerialverwaltung des Bundes im Blick der einflusssuchenden Akteure. Sie kennen die intergouvernementalen Zuständigkeiten, wissen um das federführende Ministerium, ja um die maßgebliche Abteilung mitsamt ihren Referaten ebenso wie um die konkreten Personen, die für einen Gesetzentwurf verantwortlich sind. Stets stehen aber auch die anderen beteiligten Ministerien sowie das etwaig koordinie-

36 Vgl, überblicksartig nur Paul Kirchhof, Demokratie ohne parlamentarische Gesetzgebung?, NJW 2001, S. 1332 ff. Grundlegend Thomas Puhl, Entparlamentarisierung und Auslagerung staatlicher Entscheidungsverantwortung, in: Josef Isensee/Paul Kirchhof (Hrsg.), Handbuch des Staatsrechts, Band III, 3. Auflage 2005, \$ 48. Zur Rolle des Parlaments mehr im Sinne einer Kontroll- als einer Steuerungsinstanz auf der Grundlage des Demokratieprinzips, Julian Kriper, Lawtirm - legibus solutus?, JZ 2010, S. 655 (657). Ähnlich und kritisch zum Stichwort der Entparlamentisierung Helmuh Schulze-Fielitz, Wege, Unwege oder Holzwege zu besserer Gesetzgebung, JZ 2004, S. 862 (865 f.).

37 Art. 76 Abs. 1 GG setzt dabei lediglich einen Gesetzentwurf voraus. Vorgaben zur Entstehung des Entwurfs macht die Vorschrift schon ihrem Wortlaut nach nicht. Vgl. zum von verfassungsrechtlichen Bindungen feigestellten ,inneren Gesetzgebungsverfahren" (im Gegensatz zum äußeren Gesetzgebungsverfahren) Johannes Masing, in: Herman v. Mangoldt/Friedrich Klein (Begr.)/Christian Starck, Kommentar zum Grundgeselz, Band 2,5. Auflage, München 2005 , Art. 76 Rn. 2 f. Zum dem Rechtsstaatsprinzip geschuldeter Initiativrecht der Regierung und deren Rolle siehe Julian Krüper, Lawfirm - legibus solutus?, JZ 2010, S. 655 (657), 
rende Bundeskanzleramt im Fokus der nichtstaatlichen Akteure. Auch das Justizministerium, das stets eine Rechtsförmlichkeitsprüfung vorzunehmen hat, wird jedenfalls von professionellen Akteuren frühzeitig kontaktiert, um mit (vermeintlich) verfassungsrechtlichen Argumenten das Ruder gegebenenfalls noch zu den eigenen Gunsten herumzureißen.

Daneben können aber auch die Ministerialverwaltungen der Länder ins Visier von Lobbygruppen geraten, auch wenn ihr Engagement auf die Beeinflussung von Bundesgesetzen gerichtet ist. Dies hängt mit der Mitwirkung der Bundesländer bei der Gesetzgebung des Bundes im Bundesrat zusammen und ist bei $\mathrm{Zu}$ stimmungsgesetzen folglich stärker ausgeprägt als bei Einspruchsgesetzen. Der Einfluss der Landesregierungen auf die Bundesgesetzgebung darf in solchen Fällen nicht unterschätzt werden, denn der politische Druck eines destruktiven Vetos vermittelt eine konstruktive Mitwirkungsmöglichkeit des Bundesrates, insbesondere, wenn es zum Vermittlungsverfahren kommen sollte.

\section{Judikativorgane}

Im Gesamtgefüge des nichtstaatlichen Einflusses auf die staatliche Gesetzgebung nimmt die Judikative eine Sonderrolle ein. Denn wenn die einzelnen Staatsgewalten nach der grundgesetzlichen Ordnung auch nicht streng getrennt, sondern vielfach verschränkt sind. ${ }^{38}$ ist die Judikative mit ihrer explizit verbrieften Unabhängigkeit doch stärker von den anderen Gewalten getrennt als diese untereinander. Freilich steht auch die Rechtsprechung nicht unverbunden neben der Gesetzgebung. Unabhängig von personellen Interdependenzen sind vor allem sachliche Wechselwirkungen zu konstatieren. Auslegungsbedürftige Gesetze werden durch die unabhängige Rechtsprechung konkretisiert. Im Wissen darum belässt es der Gesetzgeber zuweilen bewusst, wie es scheint, bei recht unbestimmten Rechtsbegriffen oder vielfältigen Rechtsfolgen und setzt insoweit auf die klärende Kraft der Gerichte. Für einflusssuchende Interessengruppen stehen die Gerichte gleichwohl nicht an vorderster Stelle. Dies hat vielfältige Gründe, über die sich gut und geme ein eigener Beitrag, ja eine umfassende sozialwissenschaftliche Monographie schreiben ließe. Hervorgehoben sei nur, dass die gerichtliche Kontrolle und mit ihr der über Gerichte vermittelte Einfluss stets retrospektiver Natur ist - die Gerichte können nur bestehende Gesetze korrigieren, grundsätzlich aber nicht selbst prospektiv allgemeinverbindliche Regelungen für die Zukunft erlassen. Damit ist ein zweiter Punkt angesprochen: Gerichtsentscheidun-

38 Hierzu Helmuth Schulze-Fielitz, in: Horst Dreier (Hrsg.), Grundgesetz. Kommentar, Band II, 2. Auflage, Tübingen 2006, Art. 20 (Rechtsstaat), Rn. 75 m.w.N. 
gen wirken grundsätzlich nur inter partes. Erst bei höheren bzw. höchstinstanzlichen Entscheidungen tritt eine faktische erga-omnes-Wirkung hinzu. Schließlich sind Gerichte wegen ihres streng auf die Rechtmäßigkeit fixierten Prüfungsmaßstabs und wegen der persönlichen Unabhängigkeit der Richter ungeeignetere Adressaten für die zumeist politisch motivierte Beeinflussung staatlicher Gesetzgebung als die Legislativ- und Exekutivorgane. Und außerdem bergen die Prozessordnungen manches Risiko, einen einmal angestoßenen Prozess tatsächlich in die gewünschte Richtung lenken zu können.

Nichts desto trotz sind insbesondere Rechtsanwaltskanzleien z.T. darauf spezialisiert, geeignete - und d.h. auch kostengünstige - Fälle vor die höchsten deutschen Gerichte sowie vor das Europäische Gericht und den Europäischen Gerichtshof zu bringen, deren Ausgang für den konkreten Rechtsstreit mitunter weniger bedeutsam ist als für die künftige Auslegung der streitrelevanten Norm. Andere Akteure sind an solchen Formen der nichtstaatlichen (und mittelbaren) Beeinflussung staatlicher Gesetze zumeist nur finanziell beteiligt. Häufig etwa übernimmt intern ein Verband die Verfahrenskosten für das konkrete Untemehmen, das den Streit wegen eigener (mitunter provozierter) Betroffenheit führt.

\section{Instrumente}

Wenn nach diesem Überblick ïber die staatlichen Adressaten nun erneut die Perspektive gewechselt wird und die Instrumente nichtstaatlicher Beeinflussung der staatlichen Gesetzgebung im Vordergrund stehen sollen, sind manche Wiederholungen unvermeidlich. Dies ist umso bedauerlicher, als noch nicht einmal Vollständigkeit versprochen werden kann. Doch die Mittel der Manipulation sind so mannigfach, dass auch in diesem Ausstellungsraum der Erscheinungsformen nichtstaatlicher Einflüsse auf die staatliche Gesetzgebung der Charakter eines Panoptikums beibehalten werden muss.

Im Rahmen dieses C̈berblicks sollen mit der politischen Pression (1.) und der personellen Penetration (2.) zunächst zwei primär politikwissenschaftliche Perspektiven $^{39}$ auf verschiedene Instrumente der nichtstaatlichen Einflussnahme vorgestellt werden, bevor sodann mit der Politikfinanzierung (3.), mit paktierenden (4.) und sonstigen informierenden und kommunizierenden Erscheinungsformen (5.) auch wieder rechtliche Aspekte in den Vordergrund gestellt werden. 


\section{Politische Pression}

Als politische Pression wird ein relativ drastisches Mittel der Einflussnahme auf die staatliche Gesetzgebung beschrieben, das in der gegenwärtigen Praxis der Bundesrepublik Deutschland kaum von Relevanz ist. Gemeint ist die Ausübung von Druck auf einen oder mehrere Abgeordnete, um diese zu einem bestimmten Abstimmungsverhalten zu bewegen. Der Druck kann in unterschiedlichen Intensitätsstufen erfolgen, von positiven Anreizen wie dem Inaussichtstellen von direkten Finanzzuweisungen oder Spenden über das „Inaussichtstellen eines empfindlichen Übels" bis hin zur Androhung oder Anwendung von Gewalt. Diese letzten Beispiele belegen deutlich, dass die strafrechtlichen Grenzen bei politischen Pressionen schnell überschritten werden können. Nicht zuletzt aus diesem Grund ist die gesellschaftliche Akzeptanz solcher Einflussnahme - im Deutschland der Gegenwart - ausgesprochen gering. Praktiziert wurde sie trotzdem und wird sie in abgeschwächter Form noch immer, wenngleich wohl nur noch unter Beachtung jedenfalls der straf- und vermehrt auch der parteirechtlichen Grenzen. Doch ungeachtet der gegenwärtigen Praxis in Deutschland erscheint das Instrument der politischen Pression schon aus theoretischen Gründen unbefriedigend, denn es sichert dem Einflussnehmenden keinen konstruktiv-inhaltlichen, keinen daucrhaften und auch keinen unmittelbaren Einfluss auf die Gesetzgebung und gibt ihm darüber hinaus bei nicht namentlichen Abstimmungen auch keine Kontrollmöglichkeiten an die Hand.

\section{Personelle Penetration}

Sehr viel wirksamer erscheint das Mittel der ,personellen Penetration“, bei der Interessenvertreter - beispielsweise aus einem Verband oder einem Unternehmen - in den relevanten Entscheidungsgremien platziert werden. In rechtlicher wie in tatsächlicher Hinsicht ist dabei zu differenzieren zwischen einer personellen Vertretung im Parlament auf der einen Seite und in den Regierungsorganen auf der anderen Seite.

\section{a) Parlament}

Was die Politikwissenschaft als personelle Penetration bezeichnet, ist in Bezug auf das Parlament verfassungsrechtlich gewollte, jedenfalls aber zulässige Normalität. Denn die Abgeordneten des Deutschen Bundestages sind nach dem Willen der Verfassung und des einfachen Gesetzgebers keine hauptberuflichen Mandatsträger, die während ihrer Amtszeit keinen anderen Beruf ausüben dür- 
fen, sondern normale Privatpersonen, die im Idealfall die unterschiedlichsten Berufe und mit ihnen die unterschiedlichsten Interessen repräsentieren. Dass sie nach Art. 38 Abs. 1 S. 2 GG „Vertreter des ganzen Volkes“ und „an Aufträge und Weisungen nicht gebunden sind“", zwingt sie nicht, stets im vermeintlich allgemeinen oder öffentlichen Interesse zu agieren. Vielmehr sind sie „nur ihrem Gewissen unterworfen" und nach dieser Maßgabe frei, bestimmte Partikularinteressen bei ihrem Wirken stärker in den Vordergrund zu stellen als andere. Vor diesem Hintergrund verliert der Begriff der „personellen Penetration“ jedenfalls in Bezug auf das Parlament seine Anrüchigkeit und ließe sich im Übrigen nicht an objektiven, sondern allenfalls an subjektiven Kriterien festmachen, die ihrerseits nahezu ausschließlich politischer Natur wären und von der jeweiligen politischen Opposition sicherlich anders definiert würden als von den regierungstragenden Mitgliedern des Bundestages. Im Einzelnen sei deshalb klargestellt:

Ein generelles Berufsverbot fur Abgeordnete besteht nicht, sondern ist in Art. 55 und 66 GG nur für den Bundespräsidenten, den Bundeskanzler und die Bundesminister festgeschrieben. ${ }^{40}$

Die Parlamentarier sollten sich nach dem ursprünglichen Gedanken des Grundgesetzes durch ihre normale Erwerbstätigkeit finanzieren - die Entschädigung nach Art. 48 Abs. 3 S. 1 GG war als bloße Aufwandsentschädigung zur Sicherung der Unabhängigkeit des Abgeordneten gedacht. Allerdings hat sich das Bundestagsmandat über die Jahre zur Vollzeitbeschäftigung entwickelt, sodass das Bundesverfassungsgericht 1975 im „Diätenurteil“41 entschied, dass die Entschädigung als Einkommen zu versteuern sei. Außerdem sei es mit dem Grundsatz der Unabhängigkeit der Abgeordneten nicht vereinbar, wenn Zahlungen seitens eines Unternehmens lediglich dafür geleistet werden, den Einfluss der Abgeordneten zu kaufen. ${ }^{42}$ Der im Anschluss entbrannte Streit, ob das Urteil so zu verstehen sei, dass nur solche Zahlungen verfassungswidrig seien, für die eine Beeinflussungsabsicht des Geldgebers nachgewiesen werden kann, oder schon solche, die ohne Gegenleistung des Abgeordneten erbracht werden, wurde schließlich mit einer Änderung des Abgeordnetengesetzes ${ }^{43}$ zugunsten der zweitẹn Alternative entschieden. Denn regelmäßig werden ohne Gegenleistung erbrachte Zahlungen gerade dafür geleistet, damit der Abgeordnete die Interessen des Geldgebers bei der Wahrnehmung des Amtes vertritt. ${ }^{44}$

40 Beachte insofern klarstellend $\S 44 a$ Abs. 1 S. 2 AbgG.

41 BVerfGE 40, $296 \mathrm{ff} .=$ NJW 1975, 2331 ff.

42 BVerfGE 40, 296 (318 f.) = NJW 1975, 2331 (2333).

43 Siehe den 2005 neu eingeführten $\S 44 a$ Abs. 2 AbgG.

44 Vgl. zu diesem Sinnabschnitt Hans Herbert von Arnim, Der gekaufte Abgeordnete - Nebeneinkünfte und Korruptionsproblematik, NVwZ 2006, S. 249 (250 ff). 
Das geltende Abgeordnetenrecht geht also von der Zulässigkeit von „Tätigkeiten beruflicher oder anderer Art neben dem Mandat“ aus, wie $\S 44 \mathrm{a}$ Abs. 1 S. 2 AbgG explizit festhält, will solche Tätigkeiten aber offengelegt wissen. Deshalb wird diese Regelung flankiert von Transparenzregelungen, die die Veröffentlichung von vor und während des Mandats ausgeübten Tätigkeiten sowie der Art und Höhe der Einkünfte vorschreiben. ${ }^{45}$ Mit den geschaffenen Regelungen tat der Deutsche Bundestag einen weiteren Schritt aus dem Dilemma, seine Rechtsverhältnisse selbst regeln zu müssen. ${ }^{46}$

Misstrauische Geister und solche, die nicht an eine plurale Interessenvertretung im Parlament glauben, halten diese Regelungen weiterhin für lückenhaft. In der Tat gibt es gewisse Mindestgrenzen für anzugebende Einkünfte, und Einzelspenden an Abgeordnete ${ }^{47}$ und Anstellungen nach Ausübung des Mandats, welche gegebenenfalls schon vorher in Aussicht gestellt werden, bleiben ebenso möglich wie offenes Handeln der Abgeordneten, die schon vor der Wahl als Interessenvertreter auftreten und sich auch als solche wählen lassen. Ebenso wird eine Diskrepanz zwischen den neu geschaffenen Regelungen im Abgeordnetengesetz und den tarifvertraglichen Regelungen größerer Unternehmen bemängelt, weil einige Betriebsvereinbarungen vorsehen, dass Zahlungen an bestimmte Amtsträger auch dann geleistet werden, wenn keine entsprechende Arbeitsleistung erbracht wird. $^{48}$

\section{b) Regierungsorgane}

Anders stellt sich die ,personelle Penetration“" von Regierungsorganen dar, wie sie insbesondere im Rahmen des von der Bundesregierung initiierten Programms „Seitenwechsel“" ermöglicht wurde - ein Programm, das weniger wegen der möglichen Verquickung von privaten und staatlichen Interessen als vielmehr unter dem Gesichtspunkt der Wirtschaftlichkeit später vom Bundesrechnungshof überprüft wurde. ${ }^{49} \mathrm{Im}$ Zuge dieses Programms waren im Zeitraum von 2004 bis

$45 \S 44 b$ AgbG, $\$ 18$ GOBT i.V.m. Anlage 1. Anzeigefrei bleiben Einkünfte von unter 1.000 Euro monatlich oder 10.000 Euro jährlich.

46 Vgl. dazu BVerfGE 118. 277.

47 Zum Verbot der Einflussspenden siehe unten zu 3. (Politikfinanzierung).

48 Siehe hierzu Hans Herberł von Arnim. Der gekaufte Abgeordnete - Nebeneinkünfte und Korruptionsproblematik. NVwZ 2006, S. 249 (254) und dort Fn. 37 unter Verweis auf die Betriebsvereinbarung ,BV 39 Mitarbeiter mit politischen Mandaten und ehrenamtlichen Tātigkeiten" der BASF AG i.d.F.v. 01.12.1970.

49 Bundesrechnungshof, Bericht an den Haushaltsausschuss des Deutschen Bundestags nach $\S 88$ Abs. 2 BHO über die Mitarbeit von Beschäftigten aus Verbänden und Unternehmen in obersten Bundesbehörden vom 25.03.2008 (unveröffentlicht). 
2006 zwischen 88 und 106 von Interessenträgem entsandte Personen in obersten Bundesbehörden beschäftigt. ${ }^{50}$ Entsender waren Sozialversicherungsträger, Verbănde, Gewerkschaften, private und öffentliche Unternehmen und andere Interessenvertreter. ${ }^{51}$ Bemerkenswert ist, dass nur ein Mitarbeiter von einem mittelständischen Betrieb entsandt wurde. ${ }^{52}$ Im Gegenzug wurden nur 12 bis 15 Bundesbeamte zu Interessenträgern entsandt. ${ }^{53}$ Die Mitarbeiter wurden für Zeiträume von wenigen Wochen bis zu fünf Jahren in den Ministerien beschäftigt. ${ }^{54}$ Bezahlt wurden die Mitarbeiter in $40 \%$ der Fälle von den obersten Bundesbehörden. In den restlichen Fällen zahlten die obersten Bundesbehörden nichts für den Einsatz der Mitarbeiter oder nur einen geringen Betrag. ${ }^{55}$ Eine spezielle Rechtsgrundlage war nicht vorgesehen. Die Initiative zum Einşatz der externen Mitarbeiter ging oft von den Ministerien aus. Ursprünglich sollte das Programm dem Informationsaustausch und der Weiterbildung der jeweiligen Mitarbeiter dienen. ${ }^{56}$ Praktisch gaben die Ministerien häufig Personalmangel als Grund für das Anfordem externer Mitarbeiter an. ${ }^{57}$ Die Tätigkeiten der Mitarbeiter waren unterschiedlich

50 Vgl. Bundesrechnungshof, Bericht an den Haushaltsausschuss des Deutschen Bundestags nach $\$ 88$ Abs. 2 BHO über die Mitarbeit von Beschäftigten aus Verbänden und Unternehmen in obersten Bundesbehörden vom 25.03.2008 (unveröffentlicht), S. $16 \mathrm{f}$. Aktuetlere Zahlen finden sich in den vom Bundesinnenministerium erstellten Berichten über den Einsatz externer Personen in der Bundesverwaltung. Diese Berichte wurden als Ausschussdrucksachen nicht veröffentlicht. Allerdings wurde der Erste Bericht von SpiegelOnline unter http:/Www.spiegel.de/media/0,4906,19010,00.pdf (Abruf am 05.08.2011) und der zweite Bericht unter http//carta.info/docs/2_Bericht_ueber_Einsalz_externer_ Personen_in_Bundesverwaltung.pdf (Abruf am 27.06.2010) zum Download bereit gestellt. Der dritte und vierte Bericht sind jeweils nicht öffentlich zugänglich.

51 Siehe Bundesrechnungshof, Bericht an den Haushaltsausschuss des Deutschen Bundestags nach $\$ 88$ Abs. 2 BHO über die Mitarbeit von Beschäftigten aus Verbänden und Untemehmen in obersten Bundesbehörden vom 25.03.2008 (unveröffentlichl), S. 22 f. und dort Abbildung 4. Zur genauen Verteilung auf die Ministerien siehe BT-Drs. 16/3395, S. 2 sowie $16 / 3727$, S. 3. BT-Drs. $16 / 3395$, S. 4

53 BT-Drs. 16/3395, S. 4.

54 Bundesrechnungshof, Bericht an den Haushaltsausschuss des Deutschen Bundestags nach \$8 Abs. 2 BHO über die Mitarbeit von Beschäftigten aus Verbänden und Unternehmen in obersten Bundesbehörden vom 25,03.2008 (unveröffentlicht), S. 21 f. und dort Abbildung 3.

55 Bundesrechmungshof, Bericht an den Haushaltsausschuss des Deutschen Bundestags nach $\S 88$ Abs. 2 BHO über die Mitarbeit von Beschäftigten aus Verbänden und Untemehmen in obersten Bundesbehörden vom 25.03.2008 (unveröffentlicht), S. 25 ff. und dort Abbildung 6 zur genauen Aufteiling der Leistungen.

56 Siche Pressemitteilung der Bundesregierung, Seitenwechsel - Schreibtisch tauschen, e.conomy Nr. 37, 08/2006, abrufbar unter http:/www.bundesregiening.de/nn_774/Con tent/DE/Magazine/emags/economy/2006/038/t-2-seitenwechsel-schreibtisch-tauschen. html (abgerufen ann 05,08.2011).

57 Siehe Bundesrechnungshof, Bericht an den Haushaltsausschuss des Deutschen Bundestags nach § 88 Abs. 2 BHO über die Mitarbeit von Beschäftigten aus Verbänden und Un- 
ausgestaltet. Es erfolgte auch ein Einsatz der Mitarbeiter in herausgehobenen Positionen, sodass die Mitarbeiter mit politisch bedeutsamen Fragestellungen in Kontakt kamen, teilweise Zugang zu vertraulichen, sogar ihren eigentlichen Arbeitgeber betreffenden, Informationen hatten oder ihre Tätigkeit den Interessenschwerpunkt der entsendenden Stelle betraf. ${ }^{58}$

Bemerkenswert ist hierbei, dass die Mitarbeiter auch an der Erarbeitung von Gesetzentwürfen beteiligt waren. ${ }^{59} \mathrm{Im}$ Bundesministerium für Finanzen bearbeiteten beispielsweise je ein Mitarbeiter vom Bundesverband Öffentlicher Banken, von der Kreditanstalt für Wiederaufbau und von der Deutschen Börse AG Fragen zur Anwendung und Auslegung sowie Fortentwicklung des Kreditwesengesetzes, des Finanzdienstleistungsaufsichtsgesetzes bzw. die gesetzliche Umsetzung der Finanzmarktrichtlinie." Ebenso waren (oder sind womöglich noch) seit Jahren in einer obersten Bundesbehörde von einem öffentlichen Kreditinstitut entsandte Mitarbeiter in einem für Bankenaufsicht zuständigen Referat tätig. Dabei haben sie umfassenden Zugang zu allen elektronischen und papiergebundenen Informationen der Arbeitseinheit auch über Konkurrenten der entsendenden Stelle. ${ }^{61}$ Ebenfalls bemerkenswert ist, dass die Mitarbeiter extern und intern überwiegend als Mitarbeiter der jeweiligen Ministerien auftraten ${ }^{62}$ und teilweise als Referatsleiter eingesetzt wurden. ${ }^{63}$

Die durch das Programm „Seitenwechsel“ in besonderem Maße geförderte temporäre Einbindung von Privatpersonen in die Bundesregierung wirft verschicde-

ternehmen in obersten Bundesbehörden vom 25.03.2008 (unveröffentlicht), S. $17 \mathrm{ff}$, und dort Abbildung 2.

58 Siehe Bundesrechnungshof, Bericht an den Haushaltsausschuss des Deutschen Bundestags nach $\$ 88$ Abs. 2 BHO über die Mitarbeit von Beschäftigten aus Verbänden und Untemehmen in obersten Bundesbehörden vom 25.03.2008 (unveröffentlicht), S. $23 \mathrm{ff}$. und dort Abbildung 5.

$59 \mathrm{Vgl}$. dazu nur Bundesrechnungshof, Bericht an den Haushaltsausschuss des Deutschen Bundestags nach $\$ 88$ Abs. 2 BHO über die Mitarbeit von Beschäftigten aus Verbänden und Unternehmen in obersten Bundesbehörden vom 25.03.2008 (unveröffentlicht), S. 30 f. Siehe auch Sascha Adamek/Kim Otro, Der gekaufte Staat. Wie Konzemvertreter in deutschen Ministerien sich ihre Gesetze selbst schreiben. Köln 2008.

60 BT-Drs. 16/3395, S. 3, Antwort auf Frage 3.

61 Bundesrechnungshof, Bericht an den Haushaltsausschuss des Deutschen Bundestags nach \$ 88 Abs. 2 BHO über die Mitarbeit von Beschäftigten aus Verbänden und Untemehmen in obersten Bundesbehörden vom 25.03.2008 (unveröffentlicht), Beispiel 13 auf S. 40 und BT-Drs. 16/3727, S. 5, Antwort auf Frage 8.

62 Bundesrechnungshof, Bericht an den Haushaltsausschuss des Deutschen Bundestags nach $\S 88$ Abs. 2 BHO über die Mitarbeit von Beschäftigten aus Verbänden und Unternehmen in obersten Bundesbehörden vom 25.03.2008 (unveröffentlicht), S. 44 ff.

63 Bundesrechnungshof, Bericht an den Haushaltsausschuss des Deutschen Bundestags nach $\S 88$ Abs. 2 BHO über die Mitarbeit von Beschäftigten aus Verbänden und Untemehmen in obersten Bundesbehörden vom 25.03.2008 (unveröffentlicht), S. 33 f. 
ne Probleme auf. So werden aufgrund von Sparmaßnahmen auf Personalebene Abhängigkeiten seitens der Ministerialverwaltung geschaffen, die ursprünglich nicht existierten. In Bereichen, in denen es der Verwaltung am nötigen Wissen für die Aufgabenwahmehmung mangelt, geht mit dem Einsatz extemer Mitarbeiter auch ein weitgehender Kontrollverlust einher. Die geleistete Arbeit kann ohne entsprechendes Fachwissen nicht evaluiert werden. Der Bundesrechnungshof monierte auch den Einsatz der Mitarbeiter in Bereichen mit erhöhtem Risikopotential, beispielsweise bei der Erarbeitung von Gesetzentwürfen, bei der Wahrnehmung aufsichtlicher Tätigkeiten ođer bei einem Einsatz im Leitungsbereich. ${ }^{64}$

Anhand seiner Erkenntnisse gab der Bundesrechnungshof Empfehlungen zur Regelung des Einsatzes externer Mitarbeiter in obersten Bundesbehörden ${ }^{63}$ heraus, welche schließlich in einer Allgemeinen Verwaltungsvorschrift umgesetzt wurden, ${ }^{66}$ wobei die Bundesregierung weiterhin ausdrücklich am Programm .Seitenwechsel ${ }^{64}$ festhält. ${ }^{67}$ Mit diesen Verwaltungsvorschriften wurden einige Problemquellen beseitigt. So ist der Einsatz extemer Personen nach Ziffer 2.5 der Verwaltungsvorschrift "grundsätzlich" u.a. nicht zulässig für die Formulierung von Gesetzentwürfen und anderen Rechtsetzungsakten, in leitenden Funktionen und in Funktionen mit abschließender Entscheidungsbefugnis. Allerdings können davon Ausnahmen zugelassen werden. Ein Einsatz der extemen Mitarbeiter aus Personalmangel ist nicht zulässig (Ziffer 2.6) und der Status der Person "soll grundsätzlich" intern und extern kenntlich gemacht werden. Ebenso "soll ${ }^{\text {st }}$ die Steuerung und Überwachung der Personen möglich sein. Der Einsatz der externen Personen ,soll im Regelfall" sechs Monate nicht überschreiten (Ziffer 2.3). In Hinblick auf mögliche Interessenkollisionen soll im Rahmen einer Risikoabschätzung geklärt werden, ob der Einsatz externer Personen „vertretbar" ist (Ziffer 3.1). Allein die Wortwahl deutet auf zahlreiche mögliche Ausnahmen hin, von denen in der Praxis wohl häufig Gebrauch gemacht wird. Außerdem

64 Allgemein zu den kritischen Fallkonstellationen Bundesrechnungshof, Bericht an den Haushaltsausschuss des Deutschen Bundestags nach \& 88 Abs. 2 BHO über die Mitarbeit von Beschạftigten aus Verbänden und Untemehmen in obersten Bundesbehörden vom 25.03.2008 (unveröffentlicht), S. 27 ff. sowie der Überblick auf S. 6 ff.

65 Bundesrechnungshof, Bericht an den Haushaltsausschuss des Deutschen Bundestags nach \$ 88 Abs. 2 BHO über die Mitarbeit von Beschäftigten aus Verbänden und Untemehmen in obersten Bundesbehörden vom 25.03.2008 (unveröffentlicht), S. 48 ff.

66 Allgemeine Verwaltungsvorschrift zum Einsatz won außjerhalb des öffentlichen Dienstes Beschäftigten (extemen Personen) in der Bundesverwaltung vom 17.07.2008, veröffentlicht im Bundesanzeiger Nr. 111 vom 25.07.2008. S. $2722 \mathrm{ff}$.

67 Regierungspressekonferenz vom 04.04,2008, abrufbar unter www.bundesregierung.de, Stichwort, ,Seitenwechsel“" (abgerufen am 05.08.2011). 
nennt die Verwaltungsvorschrift teilweise lediglich Zielvorgaben ${ }^{68}$ ohne die nötigen Umsetzungsinstrumente bereitzustellen, oder sie nennt lediglich kaum wirksame Instrumente. So sollen Daten-, Fernmeldc- und Geschäftsgeheimnisse vornehmlich durch „Vereinbarungen“" gesichert werden (Ziffer 6). Allerdings gilt die Verwaltungsvorschrift ihrem Anwendungsbereich nach schon nicht für entgeltliche Auftragsverhältnisse, die Beratungs- oder sonstige Dienstleistungen zum Gegenstand haben (Ziffer 1.3) - also gerade nicht für die Erarbeitung von Gesetzentwürfen in Anwaltskanzleien - und nicht für befristete Arbeitsverträge.

Letztlich setzt die Verwaltungsvorschrift die Empfehlungen des Bundesrechnungshofes nur halbherzig um und liefert insbesondere keine Lösung für die Probleme der personellen Unterbesetzung in den Ministerien für eine adäquate Aufgabenerfüllung und den drohenden Steuerungsverlust.

So kann und muss davon ausgegangen werden, dass der Einfluss externer Mitarbeiter in der Ministerialverwaltung auf die staatliche Gesetzgebung im Rahmen des Modells „Seitenwechsel“" auch seit Erlass der Verwaltungsvorschrift lediglich gedämpft, nicht jedoch ausgeschlossen, und damit immer noch aktuell ist. Letztlich kann mangels neuerlicher veröffentlichter Evaluierungen keine Aussage über den aktuellen Stand getroffen werden. ${ }^{69}$

\section{Politikfinanzierung}

Ein weiteres Instrument des mittelbaren Einflusses auf die staatliche Gesetzgebung ist die Politikfinanzierung. Sie tritt vor allem in Form der Parteienfinanzierung auf. In der stark auf die Parteien ausgerichteten Demokratie der Bundesrepublik ist unter anderem die finanzielle Ausstattung einer Partei maßgebend für ihren Einfluss. So liegt es für Interessenträger nahe, diejenige Partei zu unterstützen, die den eigenen Interessen am nächsten steht und deren Abgeordnete bei Gesetzesbeschlüssen entsprechende Entscheidungen treffen oder aufgrund Fraktionszwangs treffen müssen. Zudem kann der Ausgang einer Wahl, der maßgeblich vom Wahlkampfetat einer Partei abhängt, ausschlaggebend für die Regierungsbildung sein und damit wieder für die Gestaltung des Großteils der in der Ministerialverwaltung erarbeiteten Gesetzentwürfe. Neben der Parteienfinanzierung in diesem Sinn umfasst die Politikfinanzierung im weiteren Sinne auch die

68 Beispielsweise die wettbew'erbsneutrale Ausgestaltung des Personalaustausches in Ziffer 2.2 .

69 Die nur über inoffizielle Quellen zugänglichen Berichte des Bundesinnenministeriums (s.o.) sind wenig aufschlussreich und teilweise sogar wortgleich. 
Finanzienung der Fraktionen und der politischen Stiftungen. Beiden Finanzierungen ist gemeinsam, dass die durch sie vermittelte Einflussnahme mehrfach gemittelt ist und ihr Kontroll- ebenso wie Sanktionsmechanismen fehlen. Gleichwohl scheinen sowohl die Partejenfinanzierung im engen Sinne wie auch die Politikfinanzierung im weiten Sinne eine enorme, wenn vielleicht auch nur suggestive Anziehungskraft auf die Einflusssuchenden auszuüben. Ihr praktischer Gebrauch sollte nicht unter-, ihre praktische Wirksamkeit dagegen auch nicht überschätzt werden.

Ausgehend von der verfassungsrechtlich in Art. 21 Abs. 1 S. 4 GG normierten Rechenschaftspflicht der politischen Parteien finden sich die maßgeblichen Bestimmungen zur Parteienfinanzierung im Parteiengesetz. ${ }^{70}$ Sie werden flankiert von den allgemeinen strafrechtlichen Bestimmungen zu den Vermögensdetikten, namentlich zur Untreue. Von den vier der vom Parteiengesetz erfassten Hauptquellen der Parteienfinanzierung - Mitgliedsbeiträge (vgl. §27 Abs. I S. 1 PartG), Parteispenden ( $\$ 25$ sowie $\$ 27$ Abs. I S. 3 PartG), öffentliche Zuwendungen ( $\$ 118 \mathrm{ff}$. PartG) und Mandatsträgerbeiträge ( $\$ 27$ Abs. 1 S. 2 PartG) sind vor allem Spenden für Einflusssuchende relevant.

\section{a) Parteispenden}

Parteispenden sind grundsätzlich in unbegrenzter Höhe möglich. Eine Beschränkung sieht $\$ 25$ Abs. 1 S. 2 PartG aus Transparenzgründen lediglich für Barspenden vor, die nur bis zu einer Höhe von 1.000 Euro erlaubt sind. Auch hinsichtlich der Spender - und damit auch der Einflussnehmenden - enthält das Parteiengesetz für die vorliegende Untersuchung kaum Einschränkungen. Natürliche Personen sind fast uneingeschränkt befugt, an Parteien zu spenden. Dabei werden die Spenden zudem steuerlich begünstigt, sodass dadurch bereits ein gewisser Multiplikatoreffekt entsteht. ${ }^{71} \mathrm{Ob}$ es natïrlichen Personen dadurch möglich ist, effektiv mehr zu spenden ${ }^{72}$ ist eine Frage der Perspektive. Bemerkenswerter als diese quantitative Betrachtungsweise scheint jedenfalls der staatliche Anreiz zur Parteienfinanzierung, der in der steuerlichen Abzugsfähigkeit der Spenden zum Ausdruck kommt.

70 Zu den weiteren Arten der Politikfinanzierung. die weitgehend mit den Parteispenden zusammenhärngen siehe Hans Herbert wor Arnim, Die neue Parteienfinanzienung, DVBI. 2002 , S. $1065 \mathrm{ff}$.

71 Vgl. hierzu die Regelungen in $\$ \$ 10 \mathrm{~b}, 34 \mathrm{~g} \mathrm{EStG.}$

72 Vgl. Hans Herbert von Amim, Die neue Parteienfinanzienung, DVB1. 2002, S. 1065 (1070 f.). 
Neben natürlichen Personen können auch juristische Personen und Personenvereinigungen in unbegrenztem Maße an Parteien spenden. Was auf den ersten Blick unproblematisch erscheint, gewinnt an Brisanz, wenn man sich vergegenwärtigt, dass juristische Personen kein Wahlrecht haben. ${ }^{73}$ Gleiches gilt für Spenden von Berufsverbänden, die ebenso grundsätzlich zulässig sind. Eine Ausnahme gilt dann, wenn schon die Berufsverbände diese Spenden mit der Maßgabe erhalten haben, sie an eine politische Partei weiterzuleiten ( $\$ 25 \mathrm{Abs} .2$ Nr. 4 PartG). Diese Regelung soll aber nicht die grundsätzliche Möglichkeit der Spenden seitens der Berufsverbände beschneiden, sondern lediglich mittelbare Spenden von Unternehmen über einen Berufsverband ausschließen. Aus Gründen der Transparenz wurde zur Umsetzung des Art. 21 Abs. I S. 4 GG die Regelung der $\S \S 23 \mathrm{ff}$. PartG geschaffen, in denen den Parteien Rechenschaftspflichten hinsichtlich Herkunft und Verwendung der Mittel sowie Vermögen der Partei auferlegt werden. $\$ 25$ Abs. 3 PartG sieht zudem vor, dass Spenden über $10.000 €$ im jährlichen Rechenschaftsbericht der Parteien auszuweisen und Spenden über $50.000 €$ unverzüglich dem Präsidenten des Deutschen Bundestags anzuzeigen sind.

Die zeitliche Konnexität zwischen der Spende und ihrer Offenlegung ist allerdings teilweise durchbrochen. Denn wenn nach $\S \S 19 \mathrm{a}$ Abs. 3 S. 1, 23 Abs. 2 S. 3 PartG der Rechenschaftsbericht auch regelmäßig bis zum 30.09. des Folgejahres eingereicht werden muss, ist nach $\S 19$ Abs. 3 S. 2 PartG doch eine Verlängerung der Frist um bis zu drei Monate möglich. Anschließend wird der Bericht vom Bundestagspräsidenten als Bundestagsdrucksache verteilt, wie $\S 23$ Abs. 2 S. 3 PartG bestimmt. Damit ist aber insgesamt eine Zeitspanne zwischen Spende und Veröffentlichung von bis zu knapp zwei Jahren möglich. Die Regelungen zur Transparenz sind in ihrer Wirksamkeit weitgehend relativiert. Zudem erfolgt nur eine stark eingeschränkte Prüfung der Berichte, und bei auftretenden Ungenauigkeiten wird teilweise von zu schwachen Sanktionen ausgegangen. ${ }^{74}$ Immerhin entfällt gemäß $§ 20$ Abs. 3 S. 3 PartG der Anspruch auf staatliche Mittel, wenn kein Rechenschaftsbericht vorgelegt wird. ${ }^{75}$

73 Vgl. Hans Herbert von Arnim, Die neue Parteienfinanzierung. DVBI. 2002, S. 1065 (1068).

74 Vgl. Hans Herbert von Amim, Die neue Parteienfinanzierung, DVB1. 2002, S. 1065 (1074 ff.).

75 Für den Verfall des Wählerstimmenanteils gilt $\$ 20$ Abs. 3 S. 4 PartG. 
b) Abgeordnetenspenden

Neben den Parteispenden können die gleicher Personen auch an einzelne Abgeordnete spenden. Auch hierfür sieht das Parteiengesetz keine Begrenzung der Höhe vor. Diese Spenden müssen nicht zwangsläufig an die Partei weitergeleitet werden, sondern können vom Abgeordneten verwendet werden ${ }^{7 / 6}$ In diesem $\mathrm{Zu}-$ sammenhang ist darauf hinzuweisen, dass der Straftatbestand der Abgeordnetenbestechung ( $\S 108 \mathrm{e} \mathrm{StGB}$ ) ohne praktische Bedeutung ist, bisher noch keine Verurteilung wegen dieses Straftatbestandes erfolgte und die Norm teilweise lediglich als „symbolische Gesetzgebung“" angesehen wird. ${ }^{77}$ Eine praktisch ebenfalls nur begrenzt relevante und überprüfbare Einschränkung ist in $\$ 25 \mathrm{Abs} .2$ Nr. 7 PartG verankert. Demnach können Parteien keine Spenden annehmen, die der Partei erkennbar in Erwartung oder als Gegenleistung eines bestimmten wirtschaftlichen oder politischen Vorteils gewährt werden. Die Erkennbarkeit wird in den seltensten Fällen nachweisbar sein, ebenso wie der Kausalzusammenhang zwischen Spende und Gegenleistung.

\section{c) Konnexität zwischen Spenden und staatlicher Finanzierung}

Die Bedeutung der Spenden für die politischen Parteien wird dadurch gesteigert, dass ihre Höhe nach § 18 Abs. 1 S. 2 PartG zugleich auch die Höhe der staatlich zugewendeten Mittel beeinflusst. ${ }^{7 \sharp}$ Jährlich werden auf diese Weise insgesamt 133 Millionen $€$ unter den Parteien verteilt. Mit jedem $€$ an Zuwendung (Mitglieds- und Mandatsträgerbeitrag und rechtmäßig erlangte Spenden) erhält eine Partei, die bei der jeweils letzten Europa- oder Bundestagswahl mindestens 0,5\% oder bei einer Landtagswahl mindestens $1 \%$ der für die Listen abgegebenen Stimmen erlangt hat, auf Antrag 0,38€, wobei Zuwendungen natürlicher Personen nur bis zu einer Höhe von $3300 €$ berücksichtigt werden, $\S \S 18$ Abs. 3 S. 1 Nr. 3, Abs. 4, 19 PartG. Mit der staatlichen Zuwendung kann eine Partei so die Summe ihrer Einnahmen verdoppeln, $\$ 18$ Abs. 5 S. 1 PartG. Die Auszahlung erfolgt nach dem durchzufïhrenden Festsetzungsverfahren ( $(19 \mathrm{a}$ PartG) vom Bund durch den Bundestagspräsidenten, $\S 21$ Abs. 1 S. 1 PartG. Der Bundes-

Vgl. Hans Herbert von Arnim, Die neue Parteienfinanzierung, DVBl. 2002, S. 1065 (1069), sog. „persönliche Spende".

77 Hans Herbert von Amim, Die neue Parteienfinanzierung, DVBI. 2002, S. 1065 (1069), ders., Der gekaufte Abgeordnete - Nebeneinkünfte und Korruptionsproblematik, NVwZ 2006$, S. 249 (254 f, $)$.

78 Daneben sind die in diesem Zusammenhang weniger relevanten Größen der Erfolg der Partei bei Europa-, Bundestags und Landtagswahlen sowie die Summe der Mitglieds- und Mandatsträgerbeitrăge maßgeblich, §18 Abs. 1 S. 2 PartG. 
rechnungshof überprüft dabei sowohl die Einhaltung der Vorschriften der $\S \S 18$ ff. PartG als auch die ordnungsgemäße Durchführung der Verfahren zur Prüfung des Rechenschaftsberichts gemäß § 23a PartG (§ 21 Abs. 2 PartG).

\section{d) Strafrechtliche Grenzen der Parteienfinanzierung}

Trotz der eher großzügigen Regelungen werden teilweise auch Zahlungen auf inoffiziellem Weg an Parteien geleistet, um die maßgeblichen Vorschriften zu umgehen. Relevante Akteure sind dabei hauptsächlich finanzkräftige Unternehmen. Diese müssen ebenso wie die empfangenden Parteien dafür sorgen, dass etwaige Zahlungen unentdeckt bleiben und nicht in den Büchern zu finden sind. Dafür bedienten sich beide Seiten in der Vergangenheit (!) teilweise sog. Schwarzgeldkonten. die außerhalb der offiziellen Bücher geführt wurden.

Die Rechtsprechung hat zu einigen der ans Tageslicht gelangten Vorkommnisse grundlegende Entscheidungen gefällt und dabei zu verschiedenen strafrechtlichen Fragen Stellung genommen. Unter anderem stellt sich die Frage, wann die Einrichtung und Führung von Schwarzgeldkonten den Tatbestand der Untreue ( 266 Abs. $1 \mathrm{StGB}$ ) erfüllt. Maßgebliches Tatbestandsmerkmal dafür ist vor allem der „Nachteil" i.S.d. Vorschrift. Dieser wird weitgehend inhaltsgleich mit dem Vermögensschaden i.S.d. Betrugstatbestands verstanden und soll dann vorliegen, wenn ein Vermögensvergleich im Rahmen einer Gesamtsaldierung ergibt, dass nach einer Tathandlung weniger Vermögen vorhanden ist als vor der Handlung. Ausnahmsweise kann auch eine Vermögensgefährdung einen Nachteil darstellen, wenn sie konkret ist und wirtschaftlich bereits zu einer Minderbewertung führt. ${ }^{79}$ In der „Kanther-Entscheidung ${ }^{\text {“80 }}$ urteilte der 2 . Strafsenat des BGH zunächst, dass das pflichtwidrige Entziehen und Vorenthalten erheblicher Vermögenswerte unter Einrichtung einer treuhänderisch verwalteten ,schwarzen Kasse" durch Verantwortliche einer politischen Partei auch dann zu einem Nachteil im Sinne von $\S 266$ Abs. 1 StGB führt, wenn durch Einsatz der vorenthaltenen Mittel unter Umgehung der satzungsgemäßen Organe politische oder sonstige Zwecke der Partei nach dem Gutdünken des Täters gefördert werden sollen. Auf subjektiver Seite verlangte der Senat dafür neben einem Eventualvorsatz hinsichtlich der Vermögensgefährdung auch eine Billigung der Realisierung der Gefahr. Im „Siemens-Fall ${ }^{481}$ wurde entschieden, dass schon das Entziehen und

79 Vgl. hierzu nur Walter Perron, in: Adolf Schönke/Horst Schröder (Hrsg.). Strafgesetzbuch, 28. Auflage 2010. Rn. $39 \mathrm{ff}$.

80 Urteil des BGH vom 18.10.2006, Az.: 2 StR 499/05. BGHSt 51, 100-124.

81 Urteil des BGH vom 29.08.2008, Az.: 2 StR 587/07, BGHSt 52, 323-348. 
Vorenthalten erheblicher Vermögenswerte unter Einrichtung von verdeckten Kassen durch leitende Angestellte eines Wirtschaftsunternehmens zu einem endgültigen Nachteil im Sinne von $\$ 266$ Abs. 1 StGB führt; auf die Absicht, das Geld im wirtschaftlichen Interesse des Treugebers zu verwenden, kommt es nicht an. Erst kürzlich wurde diese Rechtsprechung auf die für die Vermögensverwaltung zuständigen $\mathrm{GmbH}$-Geschäftsführer und AG-Vorstände zwar nicht allgemein übertragen, aber geurteilt, dass, abhängig von der genauen Ausgestaltung der schwarzen Konten, ein Nachteil auch von diesen Organen zugefügt werden kann. ${ }^{82}$ Das Bundesverfassungsgericht wiederum stellte fest, dass $§ 266$ StGB aufgrund der jahrelangen gefestigten Rechtsprechung hinreichend bestimmt sei und nicht gegen Art. 103 Abs. 2 GG verstoße, und hat die Rechtsprechung des BGH damit im Wesentlich gebilligt. Allerdings müsse von den Fachgerichten auch im Falle einer Vermögensgefährdung jeweils der konkrete Vermögensschaden festgestellt werden. ${ }^{83}$ Mit dieser Rechtsprechung ist die Grenze zwischen Versuch und Vollendung sowie zwischen Gefährdungs- und Erfolgsdelikt nicht verwischt. Jahrelange Praktiken werden nunmehr allerdings strafrechtlich sanktioniert und die Nachweisbarkeit der Straftaten im Bereich der Parteienfinanzierung erheblich erleichtert.

\section{e) Wahlkampfunterstützung}

Neben dem Mittel der Spenden ist es Einflusssuchenden auch möglich, direkte Wahlkampfunterstützung zu leisten. Die Aufwendungen dafür müssen nicht als Spende ausgewiesen werden. So wurden im Jahr 1998 in sechzehn niedersächsischen Tageszeitungen ganzseitige Anzeigen mit dem Werbespruch „Der nächste Kanzler muss ein Niedersachse sein" geschaltet. Ob diese Aktion dazu beitrug, dass Gerhard Schröder zunächst Ministerpräsident Niedersachsens und schließlich Bundeskanzler wurde, mag unterschiedlich beurteilt werden. ${ }^{84}$

\section{Kooperation, Absprachen und Selbstregulierung}

Besonders wirksam kann die staatliche Gesetzgebung durch nichtstaatliche Akteure beeinflusst werden, wenn beide Seiten miteinander paktieren. Kooperationen, Absprachen und vereinbarte Selbstregulierungen sind Erscheinungsformen

82 Urteil des BGH vom 27.08.2010, Az.: 2 StR $111 / 09$ (juris).

83 Hierzu Beschluss des BVerfG, Az. 2 BvR 2559/08.

84 Bejahend Hans Herbert von Arnim, Die neue Parteienfinanzierung, DVBI. 2002, S. 1065 (1068). 
eines weniger normierenden denn vielmehr paktierenden Staates. ${ }^{85}$ Als Gründe für diesen Wandel werden das in der Parteiendemokratie vorherrschende Prinzip der Geschlossenheit nach außen, welches den Akteuren teilweise wenig Handlungsspielraum lässt ${ }^{86}$ die sich wandelnden Staatsaufgaben, welche sich nicht mit klassischen Handlungsinstrumenten wie Befehl und Zwang durchsetzen lassen, und die sinkende Steuerungskraft des Gesetzes angesehen. ${ }^{87}$ Insbesondere mit dem Argument der sinkenden Steuerungskraft begeben sich die Befürworter kooperierender Handlungsformen aber in einen Zirkelschluss, weil die zunehmenden Kooperationsformen mit ihren individual- oder partikularbetonten Interessen die gemeinwohlorientierte Allgemeinverbindlichkeit von Gesetzen in Frage stellen, was in der Folge dann wieder Raum für kooperative Handlungsformen schafft. Das Recht wird dadurch zum Tauschgut des Staates ${ }^{88}$, ohne dass informelles Staatshandeln allgemein und Kooperationen in Form von Absprachen im Besonderen rational werden müssen. ${ }^{89}$

\section{a) Akteure}

Die Akteure solcher paktierenden Erscheinungsformen, seien sie nun als Kooperationen, Absprachen oder besondere Formen der Selbstregulierung bezeichnet, ${ }^{90}$ sind begrenzt. Auf der Seite der Einflusssuchenden kommen jedenfalls mangels ausreichenden Einflusses und mangels Rechtfertigungsmöglichkeit Einzelpersonen kaum in Betracht. Umgekehrt scheidet das Parlament als Partner dieser Instrumente regelmäßig aus, denn Absprachen sind jedenfalls mit dem Plenum

Friedrich Schoch, Entformalisierung staatlichen Handelns, in: Josef Isensee/Paul Kirchhof (Hrsg.), Handbuch des Staatsrechts, Band III, 3. Auflage 2005, \$37 Rn. 30.

86 Vgl. Friedrich Schoch, Entformalisierung staatlichen Handelns, in: Josef Isensee/Paul Kirchhof (Hrsg.), Handbuch des Staatsrechts, Band III, 3. Auflage 2005, § 37 Rn. 29

87 Vgl. Friedrich Schoch, Entformalisierung staatlichen Handelns, in: Josef Isensee/Paul Kirchhof (Hrsg.), Handbuch des Staatsrechts, Band III, 3. Auflage 2005, § 37 Rn. 5, 30.

88 Zum Thema Lobbying als Tausch siehe René P. Buholzer, Legislatives Lobbying in der Europäischen Union: Ein Konzept für Interessengruppen, 1998. S. 97 ff. sowie Florian Becker, Kooperative und konsensuale Struktur in der Normsetzung. Tübingen 2005, S. $254 \mathrm{ff}$. und S. $337 \mathrm{ff}$.

89 Anders Friedrich Schoch, Entformalisierung staatlichen Handelns, in: Josef Isensee/Paul Kirchhof (Hrsg.), Handbuch des Staatsrechts, Band III, 3. Auflage 2005, § 37 Rn. 31. Rationales Handeln staatlicher Organe im demokratischen Verfassungsstaat fordert dabei das Rechtsstaatsprinzip, Andreas Voßkuhle, Sachverständige Beratung des Staates, in: Josef Isensee/Paul Kirchhof (Hrsg.). Handbuch des Staatsrechts, Band III, 3. Auflage 2005, $\S 43$ Rn. 1.

90 Umfassend zu diesem Themenkomplex bspw. nur Florian Becker, Kooperative und konsensuale Struktur in der Normsetzung, Tübingen 2005; Hans-Georg Dederer, Korporative Staatsgewalt, Tübingen 2004; Lothar Michael, Rechtsetzende Gewalt im kooperierenden Verfassungsstaat, Berlin 2002. 
schon mangels konkreter Ansprechpartner und mangels Flexibilität nicht möglich. Vielmehr ist bei diesen Instrumenten an ein Zusammenwirken zwischen Interessengruppierungen verschiedenster Art und der Verwaltung, hauptsächlich der Ministerialverwaltung, zu denken.

\section{b) Handlungsformen}

Die möglichen Handlungsformen sind um so vielfältiger, je weiter man den Begriff der Kooperation versteht. Vor allem die Regierung bedient sich in Sachverständigengremien, Kommissionen, Räten und Konsensrunden ${ }^{91}$ des Wissens nichtstaatlicher Wirkeinheiten. Die Errichtung dieser Kollegien hat regelmäßig keine Rechtsgrundlage, die gefundenen Ergebnisse haben keine rechtlich bindende Wirkung, sondern lediglich empfehlenden und beratenden Charakter. Trotzdem wirken sich die Ergebnisse zumindest mittelbar auf die Gesetzgebung aus, indem sie Gesetzentwürfen oder Neuregelungen zugrunde gelegt werden.

Im Rahmen dieser Gremien und in anderweitigen Runden werden zwischen Ministerialverwaltung, Verbänden und Unternehmen oft Absprachen getroffen. Relevante Bereiche sind hierbei vor allem das Umweltrecht und das öffentliche Wirtschaftsrecht. Als prominentes Beispiel ist der „Atomkonsens ${ }^{\star 492}$ zu nennen. Diese Absprachen können in verschiedene Kategorien eingeteilt werden. ${ }^{93}$ Sogenannte normersetzende, -vermeidende, -anwendende oder -vertretende Absprachen wirken maßgeblich im Vorfeld eines (gegebenenfalls geplanten) Gesetzgebungsvorhabens. Durch diese Absprachen wird auf die staatliche Gesetzgebung insofern Einfluss ausgeübt, als diese bereits vollkommen vermieden werden soll. Normvorbereitende Absprachen hingegen sollen ein Gesetzgebungsvorhaben im Vorfeld in einer konzertierten Aktion in bestimmte Bahnen lenken. Normvoll-

91 Hierzu Friedrich Schoch, Entformalisierung staatlichen Handelns, in: Josef Isensee/Paul Kirchhof (Hrsg.), Handbuch des Staatsrechts, Band III, 3. Auflage 2005, §37 Rn. 33 f. m.w.N. Siehe auch Paul Kirchhof, Demokratie ohne parlamentarische Gesetzgebung?, NJW 2001, S. 1332 ff. Einen umfassenden Überblick über die Erscheinungsformen bietet Andreas Voßkuhle, Sachverständige Beratung des Staates, in: Josef Isensee/Paul Kirchhof (Hrsg.), Handbuch des Staatsrechts, Band III, 3. Auflage 2005, §43 Rn. 27 ff. mit zahlreichen Beispielen für Kommissionen und Beiräte mit und ohne rechtlicher Grundlage, mit und ohne rechtlicher Entscheidungskompetenz sowie staatlich einberufenen Gremien und Gremien in privater Trägerschaft.

92 Vgl. hierzu Florian Becker, Kooperative und konsensuale Struktur in der Normsetzung. Tübingen 2005, S. $230 \mathrm{ff}$.

93 Zur Vielfalt der Typen siehe Friedrich Schoch, Entformalisierung staatlichen Handelns. in: Josef Isensee/Paul Kirchhof (Hrsg.), Handbuch des Staatsrechts, Band III, 3. Auflage 2005, § 37 Rn. 35 ff. 
ziehende oder -ergänzende Absprachen setzen an bereits vorhandener Gesetzgebung an. Beim Erlass des entsprechenden Gesetzes wird dabei regelmäßig bereits festgelegt, dass bestimmte Regelungen durch Absprachen vervollständigt werden. ${ }^{94}$ Das Problem hinter diesen Absprachen ist ihre rechtliche Wirkung. ${ }^{9.9}$ Gesetzlich sind rechtliche Wirkungen regelmäßig nicht festgeschrieben, da rechtliche Grundlagen im Normalfall gerade nicht bestehen. Die Bindungswirkung solcher Absprachen ist lediglich eine politische oder - wenn man so will - moralische. Gleichzeitig soll durch den Großteil dieser Absprachen der Gesetzgeber daran gehindert werden, überhaupt ein Gesetz zu erlassen oder, falls er tätig wird, ein Gesetz mit einem teilweise determinierten Inhalt zu erlassen. Somit bestimmt mittelbar die Regierung bzw. die Ministerialverwaltung in Zusammenarbeit mit großen Unternehmen und Verbänden, was das Parlament als Gesetzgeber zu tun und zu lassen hat.

Eng mit den Absprachen verwandt ist das Instrument der Selbstregulierung bzw. der private Normerlass. Als Beispiel hierfür mögen „DIN-Normen“ genannt seien, die vom Deutschen Institut für Normung erlassen werden. Das Deutsche Institut für Normung ist ein privatrechtlicher Verein mit dem Vereinszweck der Normung, in dem nur Unternehmen und juristische Personen, nicht jedoch natürliche Personen Mitglied werden können. ${ }^{96}$ Die geregelten Bereiche betreffen zumindest teilweise hochtechnische und sich schnell ändemde Materien, die in diesem Umfang kaum vom Parlament geregelt werden könnten. Einfluss auf die staatliche Gesetzgebung wird insofern ausgeübt, als staatliche Regelungen obsolet und ersetzt werden. ${ }^{\text {? }}$

94 Zum Themenkreis der dynamischen Verweisung unter dem Blickwinkel der Demokratie siehe Horst Dreier, in: ders. (Hrsg.), Grundgesetz. Kommentar, Band II, 2. Auflage. Tübingen 2006, Art. 20 (Demokratie), Rn. 121 f. m.w.N., sowie unter dem Blickwinkel des Rechtsstaats Helmuth Schulze-Fielizz, in: Horst Dreier (Hrsg.), Grundgesetz. Kommentar, Band 1I, 2. Auflage, Tübingen 2006, Art. 20 (Rechtsstaat), Rn. 143 f. Umfassend Ulrich Karpen, Die Verweisung als Mittel der Gesetzgebungstechnik, Berlin 1970.

$95 \mathrm{Zu}$ den verfassungsrechtlichen Rahmenbedingungen des "Gesetzgebungsvertrages" und der Art der Bindungswirkung Florian Becker, Kooperative und konsensuale Struktur in der Normsetzung. Tübingen 2005, S. 253 ff.

96 Zum Deutschen Institut für Normung siehe Andreas Voßkuhle, Sachverstāndige Beratung des Staates, in: Josef Isensee/Paul Kirchhof (Hrsg.), Handbuch des Staatsrechts, Band III. 3. Auflage 2005, $\$ 43 \mathrm{Rn} .41 \mathrm{ff}$. mit zahlreichen weiteren Nachweisen. Allgemein zu den verfassungsrechtlichen Grundlagen und Grenzen für die Übertragung von Normsetzungsbefugnissen auf nicht-parlamentarische Normsetzer Florian Becker, Kooperative und konsensuale Struktur in der Normsetzung. Tübingen 2005, S. 351 ff.

97 Zur Übertragbarkeit von Normsetzungsbefugnissen auf nicht-parlamentarische Normsetzer siehe umfassend Florian Becker, Kooperative und konsensuale Struktur in der Normsetzung, Tübingen 2005 , S. $351 \mathrm{ff}$. 
Zuletzt sind noch Selbstverpflichtungen zu nennen. ${ }^{98}$ Hauptsächlich große Industrieunternehmen erlegen sich diese auf. Darin verpflichten sich die Unternehmen häufig zum Erreichen eines bestimmten Ziels im Bereich des Umweltrechts oder des öffentlichen Wirtschaftsrechts und gleichzeitig zur Überwachung der erreichten Ergebnisse. Diese Selbstverpflichtungen sollen regelmäßig staatliche Regelungen abwenden ${ }^{99}$ Als Beispiel hierfür kann die Selbstbeschränkungszusage der Zigarettenhersteller gegenüber dem Bundesgesundheitsminister bezüglich Werbung im Fernsehen genannt werden. Nur der Bezeichnung nach handelt es sich dabei um ein einseitiges Handeln seitens des privaten Sektors ohne Teilhabe des Staates oder gar des Gesetzgebers. Dieses Bild gibt die Realität indes defizitär wieder. Tatsächlich geht selbstverständlich jeder Selbstverpflichtung ein Dialog zwischen Selbstverpflichtenden und staatlicher Seite, regelmäßig der Ministerialverwaltung, voraus. Der Unterschied zwischen Absprachen und Selbstverpflichtung liegt in der nach außen propagierten Teilhabe der staatlichen Seite. Bei Absprachen ist die Ministerialverwaltung Partner des Handelns, gleichsam Vertragspartner; ${ }^{100}$ bei Selbstverpflichtungen tritt der Staat nur gleich einem Begünstigten auf, ohne selbst offiziell eine Gegenleistung erbringen zu müssen. Dabei verzichtet er freilich informell gegenüber den sich selbst Verpflichtenden auf die Ausübung seiner Rechtsetzungsbefugnis. ${ }^{101}$

\section{Information und Kommunikation}

Die einflussreichste und am umfangreichsten genutzte Form des Einflusses auf die staatliche Gesetzgebung ist gleichzeitig auch die der Form nach einfachste. Sie besteht in der schlichten Kommunikation und der Bereitstellung von Informationen in jeweils verschiedenster Form, Dabei ist eine große Vielfalt an Arten der Kommunikation bzw. Informationsbereitstellung, an Adressaten und an Akteuren zu finden. Diese Vielfalt und die mannigfachen Kombinationsmöglichkeiten machen eine vollständige Erfassung des gesamten Spektrums oder gar eine umfängliche Kategorisierung unmöglich. Die folgende Darstellung kann jeweils

98 Hierzu Friedrich Schoch, Entformalisierung staatlichen Handelns, in: Josef Isensee/Paul Kirchhof (Hrsg.), Handbuch des Staatsrechts, Band III, 3. Auflage 2005, § 37 Rn. 37.

99 Darin ist "keine Ausübung von Staatsfunktionen im Sinne korporativer Staalsgewalt" zu sehen. Siehe hierzu Hons-Georg Dederer, Korporative Staatsgewalt, Tübingen 2004; Lothar Michael, Rechtsebzende Gewalt im kooperierenden Verfassungsstaat, Berlin 2002. S. $75 \mathrm{f}$.

100 Im Sinne eines "Gesetzgebungsvertrages" Florian Becker, Kooperative und konsensuale Struktur in der Nortrsetzung, Tübingen 2005, S. 253 ff.

101 Vgl. Hans-Georg Dederer, Korporative Staatsgewalt, Tübingen 2004; Lothar Michael, Rechtsetzende Gewalt im kooperierenden Verfassungsstaat, Berlin 2002, S. $75 \mathrm{f}$. 
nur einen Teilausschnitt beleuchten. Ein Interessenträger wird sich zur Erreichung seines Ziels, Einfluss auf die staatliche Gesetzgebung auszuüben, immer verschiedenster Instrumente, auch innerhalb der hier beschriebenen Kategorie, bedienen und dabei verschiedene Akteure ansprechen.

Innerhalb dieser Kategorie wird die Entwicklung der Einflussnahme aber besonders deutlich. Der Lobbyismus unterliegt einem stetigen Wandel durch die „Berlinisierung", Europäisierung und Globalisierung. ${ }^{102}$ Zudem tritt hier die wechselseitige Abhängigkeit der Protagonisten besonders deutlich hervor. In der heutigen Informationsgesellschaft ist Information zum Tauschgut in einem Handel mit Recht geworden.

Auch hier bietet sich wieder eine Darstellung anhand der vielfältigen und sich großteils überschneidenden Instrumente an, die aufgrund der parallelen Anwendbarkeit der Instrumente für verschiedene Akteure gegenüber verschiedenen Adressaten zwangsläufig an mangelnder Übersichtlichkeit krankt.

\section{a) Einzelgespräche}

Offensichtlichste Form der möglichen Einflussnahme ist die Nutzung persönlicher Kontakte im Rahmen von Einzelgesprächen. Aber auch in verschiedenen anderen Formen, beispielsweise in aufgearbeiteter Schriftform, können gezielt Informationen bereitgestellt werden, die Entscheidungsträger in ihrem Handeln beeinflussen können.

\section{aa) Akteure}

Als Einflussnehmende kommen für sich persönlich handelnde Einzelpersonen ebenso in Betracht wie Vertreter jeglicher organisierter Interessen und einzelner Unternehmen. ${ }^{103}$ Allerdings schwindet der Einfluss klassischer Verbände zunehmend. Die Lobbylandschaft veränderte sich maßgeblich durch den Umzug von Regierung und Parlament nach Berlin. Die Verbände werden aufgrund des Strukturwandels den Ansprüchen ihrer Mitglieder immer weniger gerecht. Statt mittel- und langfristigem, kompromissorientiertem Handeln und der Vertretung einer möglichst großen Zahl an Unternehmen unter einem Verbandsdach ge-

102 Vgl. Thomas Leif/Rudolf Speth, Anatomie des Lobbyismus, in: dies. (Hrsg.), Die stille Macht. Lobbyismus in Deutschland, Wiesbaden 2003, S. 7 (15 ff.).

103 Zu den möglichen Akteuren siehe schon oben bei III. 
winnt kurzfristiges und unternehmensorientiertes Handeln an Bedeutung. Gleichzeitig gewinnt die Exekutive immer weiter an Einfluss, sodass immer mehr Großunternehmen die Zügel selbst in die Hand nehmen oder gezielt spezialisierte Agenturen ${ }^{104}$ mit der Einflussnahme beauftragen. ${ }^{105}$

\section{bb) Adressaten}

Als Adressaten der Einflussnahme kommen einzelne Abgeordnete in Betracht. Deren Attraktivität für die Interessenträger wächst mit ihren Einflussmöglichkeiten. So sind Fraktionsvorsitzende oder Persönlichkeiten mit herausragenden Stellungen innerhalb einer Partei ebenso interessant wie Mitglieder eines bestimmten Ausschusses. Innerhalb der Ausschussarbeit gibt es eine institutionalisierte Form der Einflussnahme nach § 70 GOBT. Zur Information über einen Gegenstand seiner Beratung kann ein Ausschuss öffentliche Anhörungen von Sachverständigen, Interessenvertretern und anderen Auskunftspersonen vornehmen. Dazu kann der Ausschuss nach Abs. 2 sogar von einer Minderheit gezwungen werden, wenn sie die Anhörung verlangt. Voraussetzung, um angehört zu werden, ist eine Eintragung auf der Verbandsliste des deutschen Bundestages. Auf dieser Liste finden sich derzeit knapp 2.200 Verbände. $^{106}$

Neben der Legislative kommen als Adressaten vorliegend ebenfalls die Regierung und die Ministerialbürokratie in Betracht. In diesem Zusammenhang sind wiederum die verschiedenen Räte, Gremien, Kommissionen und ähnliche Gesprächs- und Entscheidungsgruppierungen zu nennen, bei denen sich das Tagesgeschehen neben der Kooperation selbstverständlich auch um Informationsaustausch dreht.

cc) Adressaten auf europäischer Ebene

Auf europäischer Ebene sind neben den Abgeordneten vor allem die Ausschüsse und die Kommission als Ansprechpartner interessant. Die Kommission hat die

104 Siehe dazu ebenfalls schon oben.

105 Vgl. Thomas Leif/Rudolf Speth, Anatomie des Lobbyismus, in: dies. (Hrsg.), Die stille Macht. Lobbyismus in Deutschland, Wiesbaden 2003, S. 7 (20 ff.).

106 Stand 15.07.2011. Diese ständig aktualisierte Liste ist abrufbar unter http://www.bundestag.de/dokumente/parlamentsarchiv/sachgeb/lobbyliste/lobbylisteaktuell.pdf. Zudem wird sie einmal jährlich im Bundesanzeiger veröffentlicht, abrufbar unter http://www.bundes tag. de/ dokumente/parlamentsarchiv/sachgeb/lobbyliste/lobbylisteamtlich.pdf. (letzter Aufruf am 15.08.2011). 
Zusammenarbeit mit Interessenträgern im Weißbuch „Europäisches Regieren “107 aufgegriffen und versucht, die auf sie einstürmende Masse an Interessenträgem in geregelte Bahnen zu lenken ${ }^{108}$ und einer für Brüssel spezifischen Informationskultur ${ }^{109}$ gerecht bzw. Herr zu werden. Trotzdem fehlt auf europäischer Ebene eine Kontrolle der Lobbytätigkeit vollständig. ${ }^{110}$ Auf europäischem Parkett sind weniger die Verbände, sondern vielmehr die Vertreter großer Unternehmen und vor allem Public Affairs-Agenturen ${ }^{111}$ die Hauptakteure. Diese lassen sich gemäß dem European Public Affairs Directory weiter unterteilen in law firms, political consultancies. public relations consultancies und economic and management consultancies. Aufstrebende Macht in Brüssel sind lobbyistisch agierende Anwaltsfirmen, die nach US-amerikanischem Muster arbeiten und sich als Informationsdienstleister verstehen, bei deren Tätigkeit weniger persönliche Kontakte als vielmehr professionelles Handeln im Vordergrund steht. ${ }^{112}$

Ganz allgemein lässt sich konstatieren, dass sich durch den stetigen und im Umfang wachsenden Informationsaustausch ein wechselseitiges Abhängigkeitsverhältnis entwickelt. Die Entscheidungsträger können die für ihre Entscheidungen nötigen Informationen aus der auf sie einströmenden Flut nicht filtern und greifen dabei auf die professionelle Arbeit der Informationsdienstleister zurück, die ihre Arbeit wiederum gegen Einfluss und interne Informationen von Seiten der Entscheidungsträger eintauschen. So sind die PA-Agenturen und -Kanzleien schon frühzeitig über geplante Regelungen informiert und können ihre Informationskampagnen wiederum entsprechend den Vorgaben ihrer Auftraggeber ausrichten.

dd) Adressaten auf internationaler Ebene

Auf internationaler Ebene besteht das Problem mangelnder Ansprechpartner. Hier gibt es weder Legislative noch Exekutive. Allerdings ist die Präsenz der In-

107 Europäische Kommission. Weißbuch Europäisches Regieren vom 25.07.2001, KOM (2001) 428.

108 Wertend hierzu Ulrich Hilp, Weißbuch .,Europäisches Regieren“ und Bürgerbeteiligung - Ein untauglicher Versuch auf dem Weg zu einem Europa aller Bürger?, ZG 2003, S. $119 \mathrm{ff}$.

109 Hierzu nur Thomas Hoeren, Bringt Bücher nach Brüssel - Überlegungen zur Informationskultur bei den Europäischen Institutionen, NJW 2000, S. 3112 f.

110 Thomas Leif/Rudolf Speth, Anatomie des Lobbyismus, in: dies. (Hrsg.), Die stille Macht. Lobbyismus in Deutschland. Wiesbaden 2003, S. 7 (19).

111 Siche hierzu oben unter III.

112 Thomas Leif/Rudolf Sperh. Anatomie des Lobbyismus, in: dies. (Hrsg.), Die stille Macht. Lobbyismus in Deutschland. Wiesbaden 2003, S. 7 (18). 
teressenträger, hier vor allem der Nicht-Regierungs-Organisationen (NGO), auf internationalen Konferenzen enorm groß. Auf den von der UNO veranstalteten Konferenzen sind die NGO zahlreicher vertreten als die teilnehmenden Länder. ${ }^{113}$ So können zwischenstaatlich festgelegte Ziele und Regelungen, die Eingang in die staatliche Gesetzgebung finden, frühzeitig beeinflusst werden.

\section{b) Sachverständige Beratung}

Eine besondere Form der Informationsbereitstellung oder Kommunikation ist die sachverständige Beratung des Staates. ${ }^{114}$

\section{aa) Grundsätzliches}

Sie kann als spezielle Form bzw. als Mischform angesehen werden. Sachverständigengutachten finden Eingang in die Gesetzgebung beispielsweise über die bereits dargestellten Gremien, die Ausschussarbeit und die Arbeit privater Normungsverbände. Die sachverständige Beratung dient der Idee nach der Ergänzung staatseigener Wissensorganisation und ist insofern wirtschaftlich rational. Im für den vorzubereitenden Vortrag nicht relevanten Verwaltungsverfahren ist die sachverständige Beratung teilweise gesetzlich vorgeschrieben. ${ }^{115}$ Sie kann kategorisiert werden in wissenschaftliche, technische und praktische sowie interessengeleitete Beratung. Diese Kategorisierung kann als begriffliche Aktualisierung des Spannungsfelds von sachverständiger zu interessengeleiteter Beratung gesehen werden. In Bezug auf die genannten Entscheidungsgremien ergibt sich ein weiteres Spannungsfeld zwischen bloßer Beratung und Mitentscheidung, das

113 Thomas Leif/Rudolf Speth, Anatomie des Lobbyismus, in: dies. (Hrsg.), Die stille Macht. Lobbyismus in Deutschland, Wiesbaden 2003, S. 7 (17 f.) auch allgemein zu der Entwicklung auf internationaler Ebene.

114 Umfassend hierzu Andreas Voßkuhle, Sachverstăndige Beratung des Staates, in: Josef Isensee/Paul Kirchhof (Hrsg.), Handbuch des Staatsrechts. Band III, 3. Auflage 2005, § 43. Kürzer Julian Krüper, Lawfirm - legibus solutus?. JZ 2010, S. 655 (658). Zu den möglichen vorteilhaften Auswirkungen sachverstăndiger Beratung auf die Qualität der Gesetzgebung siche Helmuth Schulze-Fielitz, Wege, Umwege oder Holzwege zu besserer Gesetzgebung, JZ 2004, S. 862 (867 f.).

115 Weiterführend mit Beispielen Marcus Schladebach, Formen institutionalisierter Mitwirkung von Wirtschaftsverbänden, DÖV 2000, S. 1026 ff. Als Beispiel soll hier nur die gutachtliche Anhörung u.a. der Fachgewerkschaften vor der Erteilung der Personenbeförderungsgenehmigung nach $\S 14 \mathrm{Abs}$. $1 \mathrm{Nr}$. 3 PBefG genannt werden. 
es für den Gesetzgeber aufzulösen gilt. ${ }^{16}$ Durch die sachverständige Beratung werden expertokratische Tendenzen verstärkt und der Bedeutungsverlust des Parlaments weiter vorangetrieben, indem Entscheidungen zunehmend auf die beratenen Gremien oder die Ministerialverwaltung ausgegliedert und im Prozess vorverlagert werden. ${ }^{117}$ Zudem begibt sich die staatliche Seite mehr noch als bereits dargestellt in eine Abhängigkeit von der externen Beratung, indem staatliche Wissensbestände vernachlässigt werden. ${ }^{118}$ Eine Überprüfung und Kontrolle der gelieferten Informationen ist ebenso schwer möglich wie die Trennung der sachverständigen von der interessengeleiteten Beratung. Dadurch droht der Gesetzgeber mit zunehmendem Informationsgefälle den Überblick über die Sinnhaftigkeit der eigenen Regelungen zu verlieren. Die gelieferten Informationen erfüllen eine „Rationalisierungsfiktion" ${ }^{\text {"19 }}$, die die aufgezeigten Handlungsmöglichkeit(en) als die einzig rationalen darstellen und so den Gesetzgeber in seiner Entscheidungs- und Handlungsfreiheit bedenklich einschränken können.

bb) Gesetzgebungsoutsourcing als besondere Form der Einbeziehung von Sachverstand

Genau an dieser Schnittstelle, etwas außerhalb der angesprochenen Gremien, Räte und Kommissionen, ist das mittlerweile oft zitierte "Gesetzgebungsoutsourcing $^{6120}$ einzuordnen, ${ }^{121}$ das Gegenstand dieses Tagungsbandes ist. Dabei lagert

$116 \mathrm{Zu}$ diesen Spannungslagen siehe Andreas Voßkuhle. Sachverständige Beratung des Staates, in: Josef Isensee/Paul Kirchhof (Hrsg.), Handbuch des Staatsrechts, Band III, 3. Auflage $2005, \S 43 \mathrm{Rn} .17 \mathrm{ff}$. und $21 \mathrm{ff}$.

117 Für eine möglichst frühe sachverständige Beratung zur Verbesserung der Gesetzesqualität, siehe Helmuth Schulze-Fielitz, Wege, Umwege oder Holzwege zu besserer Gesetzgebung, JZ 2004, S. 862 (868.).

118 Auch zu den Gefährdungspotentialen siehe Andreas Voßkuhle, Sachverständige Beratung des Staates, in: Josef Isensee/Paul Kirchhof (Hrsg.), Handbuch des Staatsrechts, Band III, 3. Auflage 2005, § $43 \mathrm{Rn}$. $50 \mathrm{ff}$.

119 Diesen Begriff bemūht Konstadinos Maras, Lobbyismus in Deutschland, APuZ 3-4/2009. S. 33 (37) unter Verweis auf Uwe Schimanek, Rationalitätsfiktion in der Entscheidungsgesellschaft, in: Dirk Tänzler/Hubert Knoblauch/Hans-Georg Soeffner (Hrsg.). Zur Kritik der Wissensgesellschaft. Konstanz 2006, S. 57 ff. Vom Ankereffekt im Sinn einer Determination der Entscheidung spricht Julian Krüper, Lawfirm - legibus solutus?, JZ 2010, S. 655 (655).

120 Diese Begrifflichkeit findet sich beispielsweise bei Ulrich Battis, Outsourcing von Gesetzentwürfen?, ZRP 2009, S. 201 f.; Julian Krüper, Lawfirm - legibus solutus?, JZ 2010, S. 655 ff.; siehe schon vorher bei Jörg Ennuschat, Wege zu besserer Gesetzgebung - sachverständige Beratung. Begründung, Folgenabschätzung und Wirkungskontrolle. DVBI. 2004, S. 986 (991); Daniel Dettinger, Wer soll Gesetze vorbereiten? - Organisationsformen der legistischen Arbeit, ZG 2002, S. 269 ff. .,Externe Erarbeitung von Gesetz- 
hauptsächlich die Ministerialverwaltung ${ }^{122}$ die Erarbeitung eines Gesetzentwurfs auf exteme Stellen, meist Rechtsanwaltskanzleien aus, und zieht so externen Sachverstand zurate. Dieses Vorgehen ist, anders als die Heranziehung extemen Sachverstands, nicht als Grundsatz, sondern als Ausnahme zu verstehen.

Die Motive für die Heranziehung extemen Sachverstands - ganz gleich in welcher Form - sind dabei unterschiedlich. Exemplarisch soll auf Folgende hingewiesen werden: Vordergründig und offensichtlich sind selbstverständlich die Einbindung vorhandenen Wissens und die Vermeidung hoher Kosten für die Aneignung eigenen Wissens. Durch die gesellschaftliche Rückkoppelung sowie qualitativ höherwertige und wirksamere Gesetze kann die Akzeptanz der Regelungen beim Wähler gesteigert werden. Die Heranziehung externen Wissens und externer Arbeitskraft kann jedoch auch einem Ressort den entscheidenden Vorsprung gegenüber einem anderen garantieren, wenn es um den Einfluss auf die Gestaltung einer bestimmten Regelungsmaterie nach den eigenen Vorstellungen geht. Nicht selten stehen die Ressorts in einem Verdrängungswettbewerb, der wie dargestellt - mitunter durch personelle Lücken geprägt sein kann. Ein ebenfalls wichtiger Aspekt, der zur Heranziehung Externer motivieren kann, ist die herausgehobene Stellung der Ministerialbürokratie gegenüber dem Parlament als eigentlichem Gesetzgeber. So scheint es möglich, dass sich die Legislative selbst aufgrund knapper Kapazitäten oder mangelnden Spezialwissens im Wettbewerb um Einfluss auf den Gesetzgebungsprozess externer Kräfte bedient.

Eine abschließende Bewertung des Gesetzgebungsoutsourcings soll an dieser Stelle nicht vorgenommen, sondern der Lektüre des Tagungsbandes überlassen werden. Eine ebenso grundsätzliche wie banale Frage sei aber schon an dieser Stelle erlaubt: Weshalb ist der Staat, der einen immensen (steuerfinanzierten) ministeriellen Sachverstand vorhält, auf vermeintliches Expertenwissen von

entwürfen" bei Helmuth Schulze-Fielitz, Wege, Umwege oder Holzwege zu besserer Gesetzgebung, JZ 2004, S. 862 (868).

121 Eine Übersicht ab dem Jahr 1999 über die Tātigkeit von Großkanzleien, welche von Bundesministerien im Rahmen der Gesetzgebung herangezogenen wurden, findet sich in BT-Drs. 16/14133. Die Drucksache enthält auch detaillierte Angaben dazu, welche Kanzlei auf welchem Feld tätig wurde. Interessant sind dabei auch die gezahlten Honorare. Die Rechtsanwaltskanzlei Hölters \& Elsing erhielt beispielsweise 1.088 .591 € für „ergänzende Beratung im Rahmen der Erarbeitung des Entwurfs eines Gesetzes zur Neuorganisation der Eisenbahnen des Bundes", siehe Anlage 4 Nr. 2.

122 Zum in diesem Zusammenhang relevanten Furiktionsvorbehalt des Art. 33 Abs. 4 GG siehe Johannes Masing, in: Horst Dreier (Hrsg.), Grundgeselz. Kommentar, Band II. 2. Auflage, Tübingen 2006, Art. 33 Rn. 62 ff. Einen Überblick über die verfassungsrechtlichen Grenzen des Gesetzgebungsoutsourcings gibt Jwhan Kräper, Lawfinn - legibus solutus?., JZ 2010, S. 655 (660 ff.). 
Anwälten angewiesen? Hat er nicht die Pflicht, jedenfalls aber die Obliegenheit, zunächst den „eigenen“ Sachverstand zu mobilisieren? Und zwar jenseits jeder demokratietheoretischen Legitimationsaspekte und beamten- und arbeitsrechtlicher Fragestellungen schlicht aus Gründen des wirtschaftlichen Umgangs mit Steuergeldern? Denn wenn der Staat seine gesetzesvorbereitende Tätigkeit mit Hilfe von Rechtsanwaltskanzleien erledigen kann, die ein einmaliges Honorar, nicht aber dauerhafte Alimentation erhalten, dann benötigt er eben entsprechend weniger beamtetes Personal. Hält er dieses dagegen vor, so muss er es auch in jedem Fall so flexibel einsetzen können, dass er auch unter - tatsächlicher oder vermeintlicher Zeitnot - handlungsfähig ist.

\section{c) Öffentliche Meinung, Medien}

Wie bereits angekündigt, tauchen auch in dem Ausstellungsraum zu den Instrumenten die öffentliche Meinung und die Medien wieder auf, die bereits in den Räumen zu den Akteuren und den Adressaten exponiert waren. Ihre Rolle lässt sich nicht klar einordnen. Sie sind Akteur, Adressat und Instrument nichtstaatlicher Einflussnahme auf die staatliche Gesetzgebung in einem. ${ }^{123}$ Dabei ist der Einfluss neuer Kommunikationsformen über das Internet in sozialen Netzwerken in diesem Zusammenhang noch weitgehend unerforscht, wird aber sowohl von staatlicher Seite als auch von nichtstaatlicher Seite verwendet. Auf staatlicher Seite sei hier nur die Heranziehung dieser Medien im Wahlkampf erwähnt. In der Bundesrepublik scheint diese Kommunikationsform auf staatlicher Seite noch den Kinderschuhen zu stecken. Als Beispiel seien der Videopodcast der Bundeskanzlerin oder die Twitter-Konten einiger Politiker genannt. Eine flächendeckende Mobilisicrung wie in den USA beispielsweise im vergangenen Präsidentschaftswahlkampf ist hierzulande noch nicht üblich, aber immerhin vermehrt vorstellbar. Bei Betrachtung dieser Kommunikationsformen ist zu bedenken, dass die Kommunikationsrichtung auch hier nicht allein von staatlicher Seite in Richtung Gesellschaft weist, sondern am Kommunikationsprozess teilnehmende politische Akteure in ihrem Handeln durch die Reaktion der sozialen Netzwerke beeinflusst werden. Schließlich tritt der Abgeordnete oder Ministeriumsmitarbeiter unmittelbar mit Wählern in Kontakt, deren Bedürfnisse es zu befriedigen gilt. Auch eine nur einseitige Einflussnahme seitens sich über modernc Kommunikationsmöglichkeiten formender Initiativen erscheint möglich und gewinnt zunehmend an Bedeutung. Bedienen sich Unternehmen oder Verbände dieser Methode und wollen Einfluss auf die staatliche Gesetzgebung ausüben, 
indem sie Bürger mobilisieren, sodass diese mit einem bestimmten Anliegen an Entscheidungsträger herantreten, wird diese Art der Einflussnahme nach USamerikanischem Vorbild als ,grassroots-campaigning ${ }^{\text {wi24 }}$ bezeichnet. Im Zusammenhang mit diesen Kommunikationsformen tritt die Diversität der Rolle der Medien im Kommunikationsprozess besonders deutlich hervor.

Wiederum einen speziellen Markt bedienen die bereits angesprochenen PAAgenturen, die nicht nur für die nichtstaatliche Seite kommunizieren und für diese gegebenenfalls politischen Druck ausüben, ${ }^{125}$ sondern auch von der Politik herangezogen werden, damit deren Akteure besser abschätzen können, welche Handlungsformen den Bürgern und den Wählern besser zu "verkaufen" sind. Aufgrund der umfangreichen Informationen der Agenturen kennen diese die auch anhand moderner Kommunikationsmedien erforschte - öffentliche Meinung ausreichend gut, um zukünftige Reaktionen und somit auch das Wahlverhalten voraussagen zu können. So können sie im Rahmen ihrer Politikberatung als Teilnehmer am Entscheidungsprozess auf staatlicher Seite Einfluss nehmen, indem sie die Akzeptanz der einen Entscheidung höher bewerten als die einer anderen Entscheidung. ${ }^{126}$

\section{Vl. Zusammenfassende Überlegungen}

Abschließend sei zunächst noch einmal betont, dass der Versuch der vorliegenden Kategorisierung nicht über die Diversität der Einflussmöglichkeiten und deren fließenden Grenzen hinwegtäuschen darf. Die sich wandelnden Staatsaufgaben sowie die Entparlamentarisierung werden kïnftig den nichtstaatlichen Einfluss auf die staatliche Gesetzgebung noch erweitern. Dagegen ist grundsätzlich nichts einzuwenden. Vielmehr ist der einflussreichste Teil, die Kommunikation, Grundvoraussetzung für einen demokratischen Prozess. Gefährliche Tendenzen

124 Zum ,grassroots-çampaigning“" allgemein und im Zusammenhang mit modemen Kontmunikationsmitteln sjele Kathrin Voss, Grassroots-campaigning und Chancen durch neue Medien, APuZ 19/2010, S. $28 \mathrm{ff}$.

125 Dazu siehe bereits oben.

126 In diesem Zusammenhang sei noch auf den aus dem Englischem stammenden Begriff des „spin-doctors" hingewiesen. Dieser betreibt ebenfalls Politikberatung, allerdings personenbezogener als beispielsweise PA-Agenturen. Ein bestimmter Entscheidungsträger oder ein Kollegium soll allgemein oder in Bezug auf bestimmte Entscheidungen in der Offentlichkeit in einem guten Licht erscheinen. Die Wirkrichtung weisı somit eher von def staatlichen Seite in die nichtstaatliche Richtung und ist damit weniger eine Form des nichtstaatlichen Einflusses auf die staatliche Gesetzgebung als eine spezielle Form der public relations-Arbeit und damit für das vorliegend darzustellende Thema von eher untergeordneter Bedeutung. 
sind dort erkennbar, wo die Transparenz der Prozesse über das Maß hinaus eingeschränkt ist, das für eine vertrauliche Zusammenarbeit notwendig ist. Dann wird die Entscheidungsfindung auf dem Weg zu einem neuen Gesetz zu einem elitären Prozess mit oligarchischen und expertokratischen Tendenzen, der mangels Evaluationsmöglichkeiten auf staatlicher Seite Entscheidungen ermöglicht, die nicht dem Allgemeinwohl, sondern dem Wohl organisierter Interessen dienen. Eine umfassende Institutionalisierung des nichtstaatlichen Einflusses auf die staatliche Gesetzgebung ist dabei abzulehnen und scheitert schon an der Fülle der Instrumente. ${ }^{127}$ Möglich und sinnvoll sind indes maßvolle Transparenzregelungen.

Darüber hinaus mag der Rundgang durch dieses Panoptikum von Erscheinungsformen nichtstaatlichen Einflusses auf die staatliche Gesetzgebung auch mit Blick auf das Oberthema des Tagungsbandes in sechs kurzen Überlegungen resümiert werden.

\section{Priorität politischer Parteien}

Die überkommene und verfassungsrechtlich jedenfalls zulässige, vielleicht sogar gewollte politische Willensbildung ist durch eine Priorität der politischen Parteien gekennzeichnet. Sie sind es nicht nur, die diesen Willen formulieren, artikulieren und personalisieren, sie tragen ihn auch jedenfalls dann direkt in die Gesetzgebungsorgane, wenn sie in ihnen vertreten sind. Neben dieser parteiinternen Willensbildung fungieren die Parteivertreter auch als wichtige Ansprechpartner für sonstige nichtstaatliche Akteure, die ihre Interessen bei der staatlichen Ge-

127 Eine umfassende Institutionalisierung der Beteiligung nichtstaatlicher Akteure besteht in der Schweiz. Nach Art. 147 Bundesverfassung der Schweizerischen Eidgenossenschaft werden die Kantone, die politischen Parteien und die interessierten Kreise bei der Vorbereitung wichtiger Erlasse und anderer Vorhaben von großer Tragweite sowie bei wichtigen völkerrechtlichen Verträgen zur Stellungnahme eingeladen. Dies ist der speziellen schweizerischen Gesetzgebungskultur geschuldet und nicht auf das deutsche Rechtssystem übertragbar. Die schweizerische Demokratic ist wesentlich direkter und weniger repräsentativ ausgestaltet als diejenige des Grundgesetzes. Neben einem vom Volk initiierten Gesetzgebungsprozess nach Art. 138 und 139 bestehen in der Schweiz sowohl obligatorische (Art. 140) als auch fakultative Referenden (Art. 141). Dabei erhält jeweils das Volk die Gelegenheit, über bestimmte Gesetzesentwürfe abzustimmen. Aus diesem Grund sind eine Vielzahl an Gesetzentwürfen in besonderem Maße kompromissbedürffig, sodass zur Vermeidung unnötiger legistischer Arbeit und von Zeitverlusten eine Beteiligung auch privater Interessensgruppen im Vernehmlassungsverfahren als Teil des Gesetzgebungsverfahrens notwendig ist. Dadurch wird der Entwurf "referendumsfest" gemacht. Das Verfahren ist am ehesten vergleichbar mit der Anhörung in den Ausschüssen nach $\$ 70$ GOBT. 
setzgebung vertreten und im besten Falle auch durchgesetzt sehen wollen. Die wichtigste Erscheinungsform nichtstaatlichen Einflusses auf die staatliche Gesetzgebung liegt also in der Arbeit der politischen Parteien.

Angesichts dieser herausragenden Rolle der politischen Parteien bei der politischen Willensbildung müssen ihnen andere Erscheinungsformen nichtstaatlicher Einflüsse auf die staatliche Gesetzgebung, bei denen sie nicht mehr oder nur noch mittelbar eingebunden sind, mindestens als Konkurrenz, möglicherweise gar als Angriff auf ihre prioritäre Position in der politischen Meinungsbildung erscheinen. Das gilt für direktdemokratische Erscheinungsformen ebenso wie für die skizzierten sonstigen Erscheinungsformen, bei denen politische Parteien eine, aber eben nicht mehr zwingend die maßgebliche Rolle spielen. Verfassungsrechtlich sind die politischen Parteien vor einem etwaigen Bedeutungsverlust nicht geschützt, ist ihnen doch nur die „Mitwirkung“ an der politischen Willensbildung, nicht etwa das Monopol der politischen Willensbildung zugewiesen. Sie müssen deshalb politisch um den Erhalt ihres Einflusses kämpfen, und sie tun dies, indem sie sich auch an den anderen Erscheinungsformen nichtstaatlichen Einflusses auf die staatliche Gesetzgebung beteiligen. Besonders sichtbar wird dies, wenn politische Parteien direktdemokratische Elemente, namentlich Volksabstimmungen, für ihre eigenen politischen Zielvorstellungen instrumentalisieren. So wenig sich dies rechtlich verhindern lässt, so sehr ist doch auf die Widersprüchlichkeit hinzuweisen, die damit einher geht, weil Volksinitiativen etc. häufig gerade deshalb von engagierten Bürgern auf den Weg gebracht werden, um jenseits parteipolitischer Motive eine ganz bestimmte Sachfrage zu klären.

Vor diesem Hintergrund relativiert sich möglicherweise auch die ganze Aufregung um ein Gesetzgebungsoutsourcing an Rechtsanwaltskanzleien. Bei allen rechtlichen, auch verfassungsrechtlichen Problemen, die im Rahmen dieses Tagungsbandes zur Sprache kommen, muss doch jedenfalls eine Motivation der die Rechtsanwaltskanzleien beauftragenden Gesetzgebungsorgane bedenklich stimmen: Wenn Rechtsanwälte - denkbar wären auch Hochschullehrer - mit der Ausformulierung und Begründung eines Gesetzesentwurfs ganz bewusst beauftragt werden, um außerhalb der Ministerialverwaltung oder außerhalb der Bundestagsausschüsse Sachfragen zu klären, die in diesen Gremien wegen parteipolitischer Determinierung nicht oder nicht sachgerecht geklärt werden können. wenn also das Gesetzgebungsoutsourcing gerade aus dem Grund erfolgt, parteipolisch bestimmte Vorgaben zu umgehen, um sachpolitisch bestimmte Vorschriften zu erlassen, dann stellt sich dies als massiver Einflussverlust der politischen Parteien dar. 


\section{Gesetzgebungsbeeinflussung als Grundrechtsausübung}

Dieser Einflussverlust der politischen Parteien mag unterschiedlich bewertet werden. Bei rechtlicher, ja bei verfassungsrechtlicher Betrachtung ist jedenfalls aber festzuhalten, dass die nichtstaatliche Beeinflussung staatlicher Gesetzgebung grundsätzlich nichts Schädliches oder gar Verbotenes ist, sondern sich vielmehr ganz umgekehrt als Grundrechtsausübung darstellt. Die politischen Grundrechte, allen voran die Kommunikationsfreiheiten und die Versammlungsfreiheit, sichern dem Einzelnen gerade die Möglichkeit, sich an der politischen Willensbildung zu beteiligen, sei es als Individualperson, sei es im Verbund mit anderen und organisiert als Verein. Verband oder bloße Versammlung. Die grundrechtlichen Freiheiten reichen dabei weiter als bis zur bloßen Willensbildung, sie zielen doch gerade auch darauf, den dieserart gebildeten Willen in die Gesetzgebung einfließen zu lassen. Jede Art der Interessenvertretung ist entgegen der negativen Konnotation des Lobbyismus in Deutschland deshalb grundrechtlich nicht nur zulässig, sondern in der freiheitlich demokratischen Grundordnung des Grundgesetzes geradezu gewollt.

\section{Tendenz zur Formalisierung}

Die bloße Ausübung von Freiheit erscheint in Deutschland zuweilen befremdlich, solange sie nicht rechtlich hinreichend flankiert ist. Mitunter kann auch mit Blick auf den nichtstaatlichen Einfluss auf die staatliche Gesetzgebung gerade der Eindruck entstehen, nicht die Beschränkung von Grundrechten durch den Staat, sondern ihr Gebrauch durch den Bürger müsse gerechtfertigt werden. Dieser Eindruck entsteht jedenfalls dann, wenn die Beeinflussung der staatlichen Gesetzgebung durch nichtstaatliche Akteure (außerhalb der politischen Parteien) solange verpönt wird, wie er nicht durch Vorschriften „legalisiert“ ist. Insofern lässt sich jedenfalls zum Teil eine Tendenz zur Formalisierung feststellen. Dabei kann der Wunsch nach einer Regulierung der verschiedenen Einflussnormen durchaus begründet sein. Denn ob die Anhörung von Verbänden oder anderen Akteuren im Gesetzgebungsverfahren nun in der Geschäftsordnung eines obersten Bundesorgans oder einer Rechtsverordnung oder in einem Gesetz verankert ist - stets kann die Normierung weniger auf die generelle Gestattung als vielmehr auf grundsätzliche Gleichbehandlung gerichtet sein. Auch der Wunsch nach Transparenz mag ein Grund dafür sein, warum immer wieder die Forderung nach einem Gesetzgebungsverfahrensgesetz erhoben wird, in dem die Anhörungs- und Mitwirkungsrechte nichtstaatlicher Akteure - womöglich noch abschließend - normiert sind. Die Vorstellung, dass die faktische Einflussnahme normativen Vorgaben folgt, mag sich freilich schnell als Illusion erweisen. Auch 
deshalb sollte man sich des Verhältnisses von grundrechtlicher Freiheit zu gesetzlicher Formalisierung stets bewusst sein.

\section{Konkreter Konsens statt abstrakter Akzeptanz}

Nicht jede Form des nichtstaatlichen Einflusses auf die staatliche Gesetzgebung wird wohl überwiegend so negativ gesehen wie etwa das Lobbying. Andere Formen stehen in der Gunst der öffentlichen Meinung und werden begrüßt. Kooperative Gesetzgebung bspw. ist grundsätzlich wohl positiv konnotiert (wohingegen der weitgehend inhaltsgleiche Begriff der paktierten Gesetzgebung wohl eher ein negatives Image hat), und auch die besondere Einbindung von „Betroffenen" in das Gesetzgebungsverfahren wird immer wieder fordernd thematisiert. Bei allen Vorteilen einer - womöglich rechtlich regulierten und d.h. formalisierten - Einbindung bestimmter privater Akteure in die staatliche Gesetzgebung muss dabei doch auf die Gefahr aufmerksam gemacht werden, dass dem Gesetzgeber ein konkreter Konsens mit den „Betroffenen“ wichtiger ist als die abstrakte Akzeptanz hoheitlicher Gesetze. Dies mag in Fällen gerechtfertigt sein, in denen das Gesetz einen sachlich engen Anwendungsbereich hat und der Kreis der Betroffenen deshalb präzise definiert werden kann.

\section{Relativierung der Allgemeinheit von Gesetzen}

In allen anderen Fällen führt eine derartige Präferierung zu einer Relativierung der Allgemeinheit von Gesetzen und damit zu einem Verlust ihrer Steuerungskraft. Denn wenn die Verbindlichkeit staatlicher Gesetze weniger auf der allgemeinen Akzeptanz verfassungsmäßig erlassener und also mit demokratischen und rechtsstaatlichen Vorgaben im Einklang stehender Normen als vielmehr auf einem konkreten Konsens beruht, werden Gesetze mittel- bis langfristig nur noch von denen als verbindlich empfunden, die an dem jeweiligen Gesetzesverfahren konkret beteiligt waren. 


\section{Verantwortungsfragen}

Der nichtstaatliche Einfluss auf die staatliche Gesetzgebung wirft schließlich zahlreiche Verantwortungsfragen auf, die hier nur gestellt sein mögen. Wer trägt überhaupt die Verantwortung für ein Gesetz? Wer trägt die Verantwortung für ein Gesetz, das inhaltlich maßgeblich durch nichtstaatliche Akteure beeinflusst wurde? Wer trägt die Verantwortung für ein Gesetz, das auf einem Konsens zwischen den Normunterworfenen und dem Normgeber beruht? Und wie kann die Verantwortung jeweils eingefordert werden? 